\title{
Análisis de la movilidad urbana de una ciudad media mexicana, caso de estudio: Santiago de Querétaro
}

\section{Urban mobility analysis of a mexican middle city, case study: Santiago de Querétaro}

\author{
Saúl Antonio Obregón-Biosca \\ Eduardo Betanzo-Quezada*
}

\begin{abstract}
Urban planning policies require knowledge provided by mobility studies. Answer questions as: what are the patterns of trips? or, what are the reasons for our trips? Among others, show information about the current territorial situation. This work examines current trip patterns in the urban area of Queretaro, gathered from an origin-destination survey. Data were analyzed through descriptive statistics and causal relationships between transport and socio-economic characteristics of individuals. Results show the trips patterns, reasons and preferences on the existing means of transportation, being income a significant factor of modal choice.
\end{abstract}

Keywords: urban trips, means of transportation, population, Mexico.

\section{Resumen}

Las políticas de ordenación urbana territorial requieren del conocimiento que aportan los estudios de movilidad cotidiana. Responder preguntas del tipo ¿̨cuáles son los patrones de desplazamientos? o ¿qué medio empleamos?, entre otras, refleja información sobre la situación espacio-territorial actual. Este trabajo analiza los patrones actuales de los desplazamientos en la Zona Conurbada de Querétaro (zCQ) a partir de una encuesta origen-destino, mediante estadística descriptiva y relaciones causales entre el transporte y las características socioeconómicas. Los resultados revelan los patrones, motivos y preferencias en los medios de transporte existentes, al respecto, el ingreso es un factor significativo en la elección del medio.

Palabras clave: viajes urbanos, medios de transporte urbanos, población, México. 


\section{Introducción}

La movilidad es una necesidad básica del ser humano porque el desplazamiento de un punto a otro permite al individuo realizar sus tareas cotidianas; por otra parte, el transporte es un bien altamente cualitativo y diferenciado y existen viajes con distintos propósitos y a diferentes horas del día.

La dinámica de las ciudades modernas se caracteriza por altos índices de movilidad de personas y bienes, dinámica que se asocia a la dimensión física de las actividades de la población y a su distribución territorial: mientras más crece la ciudad, más induce a realizar desplazamientos de mayor longitud. Sin embargo, la longitud de esos desplazamientos en las grandes ciudades inhibe o dificulta la posibilidad de realizarlos a pie, por lo que se recurre a un modo de transporte que reduzca el tiempo de su trayecto (Rabaza, 2009).

Así, es indudable que en las grandes ciudades resulta necesario un sistema de transporte eficiente y adecuado para atender las necesidades de la población, un sistema que posibilite, de manera adecuada, la movilidad y accesibilidad en las actividades realizadas. Si bien la dotación de transporte en algunas ocasiones influye de forma indirecta como potencializador del crecimiento económico y social en un área dada (ObregónBiosca, 2010), en el aspecto laboral su carencia también puede constituir una barrera (por costos, cobertura, entre otros) que impida a potenciales trabajadores acceder al empleo. Sobrino (2007) expone que las mejoras en el transporte y el cambio en la accesibilidad como producto de obras viales influye directamente en el comportamiento de los desplazamientos por motivo de trabajo.

El objetivo de esta investigación es determinar los patrones de viaje y su correlación con las características socioeconómicas de los habitantes de la Zona Conurbada de Querétaro (zCQ), en México, partiendo de las siguientes tres hipótesis: en la primera, el ingreso es el factor determinante para la elección del medio de transporte; la segunda sugiere que el usuario del transporte privado no encuentra incentivos y condiciones para utilizar los medios masivos y no motorizados; y la tercera propone que las características de explotación del sistema de transporte público desalientan su uso a los no usuarios del medio.

A continuación se exponen algunos elementos que permiten estructurar un marco de referencia, en el contexto de trabajos realizados por investigadores iberoamericanos, con el propósito de seleccionar las variables más significativas para su aplicación en un caso de estudio. 


\section{La movilidad y accesibilidad en entornos urbanos}

Las personas se mueven constantemente por las ciudades con diferentes motivos de viaje: trabajo, estudio, salud, ocio, entre otros (Merlin, 1996). En una perspectiva más amplia, Henry (1998) trata el concepto de movilidad como la manera en que un individuo realiza un programa de actividades en sus dimensiones espaciales y temporales. Así, un viaje responde a cierto motivo y utiliza un determinado medio a una hora específica del día.

Ahora bien, las transformaciones territoriales en las que están inmersos los espacios metropolitanos permiten alcanzar un número de destinos más dispersos y alejados del hogar para realizar un mayor número de actividades (Gutiérrez y García, 2005). Así, la movilidad se materializa a nivel espacial en los desplazamientos generados en virtud de las necesidades cotidianas de los individuos. Mientras que los desplazamientos son el resultado de la ubicación del hábitat y de las actividades, su distribución en el área urbana da lugar a la separación de los puntos origen y destino que son la causa de dichos movimientos (Valero, 1984).

Por su parte, Ortúzar y Willumsen (2008) definen el concepto de movilidad como una medida de la facilidad o dificultad de realizar desplazamientos de un origen a un destino específico, mientras que Giacobbe et al. (2009) mencionan que ésta cumple un rol muy importante en el análisis del desarrollo urbano, y que permite una doble lectura: puede ser entendida como la facilidad o dificultad con la que las personas acceden a lugares, o como la posibilidad o imposibilidad de acceder a servicios y lugares.

En este sentido, el sistema de transporte en una ciudad debe resolver las necesidades principales de los ciudadanos (comida, mercado, trabajo, salud y educación) de forma sostenible. Por ello, Pardo (2005) insiste en que la accesibilidad es el principal factor en la movilidad, y la define como la disponibilidad de un ciudadano para movilizarse y la posibilidad de acceder a sus necesidades.

La accesibilidad potencializa las oportunidades de empleo, tal como Suárez y Delgado (2007) lo analizan obteniendo que las zonas con mayor accesibilidad tienden a tener una producción más alta por trabajador y los estratos de ingreso bajo tienen menores oportunidades de empleo en cercanía al lugar de residencia, lo que los obliga a pagar una alta proporción de sus ingresos en transporte para encontrar empleo formal. Como ya se mencionó en la primera hipótesis, el análisis realizado en el presente trabajo reforzará la magnitud que tiene el ingreso como factor determinante en la elección del medio de transporte. 


\subsection{Los entornos urbanos y la conformación de los transportes}

La movilidad cotidiana es un elemento de gran interés en el estudio de diferentes temas que van desde el transporte urbano hasta la estructura urbana, en este sentido, Casado (2008) realiza una revisión crítica de las diferentes fuentes de información e investigaciones desarrolladas en México que utilizan el análisis de la movilidad cotidiana de la población, las cuales coinciden en que frecuentemente se replican en los ámbitos metropolitanos los problemas asociados a una creciente población y movilidad.

El modelo urbano desempeña un papel central en los costos de transporte, en este sentido, Fuentes (2009) realiza una investigación en Ciudad Juárez, México; identificó que las zonas de menores ingresos son las que emplean con mayor frecuencia el transporte público y en ellas se realiza un menor número de viajes motorizados por persona al día, con tasas de entre 0.54 y 0.88 , mientras las zonas con ingresos medianos y altos emplean de forma intensiva el vehículo privado con tasas de entre 0.92 a 1.8.

La correlación entre la estructura espacial urbana y el transporte se muestra reflejada en la duración y la distancia del viaje, influyen factores como la alta densidad de la población, el valor del suelo, la tenencia de la vivienda, el balance entre empleos y hogares y la proporción de casas alquiladas.

El efecto del policentrismo se explica en el hecho de que los trabajadores periféricos se trasladan a los subcentros y no al distrito central de negocios; entonces, al disminuir los costos de viaje los establecimientos suburbanos tienen la oportunidad de disminuir el salario. Fuentes (2009) concluyó, en su caso de estudio, que la localización espacial de los trabajadores y empleos son consistentes con las predicciones de los modelos neoclásicos de la economía urbana de Alonso (1964), Mills (1972) y Muth (1969), ya que observó que la población con mayor ingreso eligió vivir más cerca de su centro de trabajo porque tiene posibilidades de pagar costos de suelo más altos, disminuyendo sus tiempos de trayecto al centro laboral.

La población con menor ingreso se asienta en las áreas de bajos valores del suelo, a mayor distancia de los centros laborales, lo cual influye en el incremento de sus costos de viaje. No obstante, identificó que el proceso de descentralización del empleo no significó menores tiempos de viaje. El contexto que analizó presenta distorsiones, ya que los trabajadores no se establecieron cerca de los centros de empleo en respuesta al alto costo del suelo urbano, inducido a la vez por la localización de dicho tipo de actividades, este costo influyó en la decisión de establecer sus viviendas a mayor distancia con el consecuente incremento en el costo del viaje. Lo anterior confirma lo expuesto por Giuliano y Small (1993), pues la deci- 
sión de las personas a localizar su residencia cerca de su lugar de trabajo depende de factores diferentes a los costos de viaje.

Por su parte, Suárez y Delgado (2010) emplearon modelos estadísticos para analizar la movilidad residencial en la ciudad de México sosteniendo, al observar influencia del lugar de trabajo sobre la elección de residencia, que existe un proceso de co-localización entre empleos y vivienda.

Susino et al. (2007) analizan los factores relacionados como causas, y también como consecuencias, del incremento de movilidad en Andalucía; obtienen que la causa principal de la transformación de la organización y estructura del sistema urbano es consecuencia parcial de cambios en la estructura ocupacional y de los mercados locales de trabajo; así dichos factores han contribuido al aumento de la movilidad.

Ahora bien, un enfoque del transporte público de personas, desde una perspectiva hacia los trabajadores según Ocaña y Urdaneta (2005), indica que éste se asegura la movilidad desde la residencia al empleo, y que, al ser masivo, condiciona en gran medida la actividad y la economía urbana; por lo anterior, reflexiona acertadamente que el transporte no es un fin en sí mismo, sino un medio para mejorar las condiciones de vida de una ciudad. Concluye que la política no debe centrarse en el concepto simplista de movilizar a los usuarios, sino de incrementar de manera global el bienestar de los habitantes y la productividad urbana.

\subsection{El sistema de transporte urbano}

Ortúzar (2000) define al Sistema de Transporte Urbano como la interacción de una red (infraestructura), un sistema de gestión y un conjunto de medios que compiten o se complementan. Ocaña y Urdaneta (2005) lo conciben como la vinculación de tres subsistemas que son transporte público, tráfico e infraestructura vial y de transporte en el ámbito urbano. El subsistema de transporte público incluye la prestación del servicio (infraestructuras, vehículos, organizaciones operadoras, autoridades de tutela como ministerios, gobiernos regionales y locales), los usuarios (organizados o no), las relaciones entre ellos y el marco legal. A partir de lo anterior, a continuación se realiza una breve reflexión general sobre los medios de transporte analizados en el caso de estudio presentado en este artículo.

Respecto a un sistema de transporte público, su objetivo, según Mundó (2002: 209), es "el traslado eficiente, cómodo y seguro de personas entre los distintos lugares donde se emplazan y desarrollan las actividades urbanas, facilitando la integración entre ellos". Debido a las características económicas propias de los países en desarrollo, el transporte colectivo urbano se presenta como el medio de transporte predominante y, como 
menciona Pardo (2005), por tener una organización informal y desorganizada que induce efectos ambientales negativos y de seguridad; señala que para que este medio de transporte sea sostenible requiere de un trabajo de fondo sobre las organizaciones y su formalidad así como de su sostenibilidad en términos económicos, ambientales y sociales. Existen experiencias respecto a reestructuraciones de sistemas de transporte público como en García (2006) y Rojas y Mello (2005), quienes coinciden en la necesidad de que los transportes colectivos urbanos sean de calidad en las ciudades de países en desarrollo.

La finalidad de las vialidades es generar accesibilidad y permitir la movilidad de las personas, no obstante, en la mayoría de las ciudades de México se favorece el transporte en vehículos privados dejando a un lado políticas enfocadas al transporte masivo. En el caso de Santiago de Querétaro. $44.93 \%$ de los desplazamientos en la ciudad se realizan en automóvil privado (ya sea como conductor o acompañante), en este sentido Rabaza (2009) advierte que el empleo prioritario del automóvil como medio de transporte motivará la saturación de las vialidades, y Delgado et al. (2003) detallan que otros factores que inducen la congestión vial incluyen una infraestructura vial inadecuada, incompleta y carente de continuidad.

Pardo (2005) describe al automóvil como el enemigo principal del transporte sostenible al citar a autores como Cervero (1998) y Gannon et al. (2001); dicha afirmación la sustenta bajo los siguientes argumentos: es individual, tiene un elevado costo, genera desigualdad, implica una inversión muy grande para muy pocos (en términos de infraestructura urbana), y necesita de mucho espacio urbano para subsistir. Además, tiene desventajas en el mayor nivel de accidentalidad, baja capacidad (máximo cinco pasajeros), influye en la dispersión urbana, y está correlacionado con la depresión de los habitantes.

El medio de transporte no motorizado es definido por Pardo (2005) como individual y privado (lo mismo que el automóvil y la motocicleta). Expone que esta categoría incluye la bicicleta, caminar y patinar. Para él, caminar es el medio de transporte que menor energía requiere, es autopropulsor, la única necesidad para existir es el cuerpo y la gran mayoría de las personas utilizan este medio durante algún momento de un día. Menciona como desventaja la reducida velocidad (cinco km/h) y la dificultad para cubrir grandes distancias (Hook, 2003).

Valero (1984) menciona que los desplazamientos que se realizan a pie son los más frecuentes en cualquier circunstancia, y los relaciona directamente con la edad de las personas; afirma que estos viajes aumentan progresivamente conforme aumenta la edad, las personas mayores 
de 65 años son las que realizan la mayor proporción de viajes a pie, porque de alguna manera disminuyen sus actividades de largas distancias.

Pardo (2005) apunta que la bicicleta es un medio en el cual es posible recorrer distancias medias (varia la distancia dependiendo de la condición física del usuario), enlista ventajas: no emite polución directa, bajo costo de mantenimiento o uso, requiere poco espacio urbano, y genera poca accidentalidad en su mayoría de bajo impacto (en comparación con los motorizados). Finaliza aseverando que su uso es una actividad física que mejora la salud, así como una forma de recreación.

\section{Descripción del ámbito de estudio}

La zCQ se localiza en el estado de Querétaro de Arteaga, en el centro de México, territorialmente está inmersa en tres municipios: Corregidora, El Marqués y Santiago de Querétaro. En coincidencia con otras áreas en América Latina, la de Querétaro ha mostrado recientemente una expansión territorial muy drástica. Si bien demográficamente ha crecido a ritmos mayores que otras áreas urbanas mexicanas similares (de 456,458 habitantes en 1990 a 801,940 en el 2010) la extensión de la superficie donde se ubican las actividades que pueden considerarse incorporadas a este conglomerado ha crecido a ritmos mucho mayores.

La mancha urbana de la zona experimentó un intenso crecimiento en las décadas recientes, pues en 1970 su superficie era de $31 \mathrm{~km}^{2}$, mientras en 1992 alcanzó los $101 \mathrm{~km}^{2}$ y para el año 2002 llegó a los 130 km² (Cobo, 2008). Este diferencial en los ritmos de crecimiento demográfico y territorial se expresa, de manera obvia, en la reducción de la densidad poblacional por unidad de superficie. Tan sólo este decremento de la densidad, sin tomar en cuenta otros elementos, implica el surgimiento de modificaciones relevantes en diferentes situaciones que tienen que ver con la movilidad.

Si se considera que las dinámicas de ubicación habitacional y de emplazamiento de centros de trabajo se han mantenido de forma relativamente autónoma y siguiendo las prevalentes en 1970, se infiere que los desplazamientos crecieron en extensión. No es sólo el alargamiento de los viajes el único efecto de este crecimiento desmesurado del territorio ocupado por actividades urbanas, ni su equivalente incremento en tiempo de viaje, tasa de motorización, y desgaste vehicular de los propios pasajeros y automovilistas, o la inferencia que de ahí puede derivarse: peores situaciones de congestión, contaminación y accidentalidad (cuestiones que tendrán que ser demostradas y cuantificadas), sino que posiblemente las prácticas de movilidad han sido modificadas de manera diversa. 


\subsection{Diagnóstico del transporte de personas en el ámbito de estudio}

A partir de la década de los ochenta del siglo pasado comienzan a perfilarse los primeros signos de una ocupación diferente en el sentido de que las empresas industriales no necesariamente se instalaron en la mancha urbana ya constituida o en sus inmediaciones, sino en cierta lejanía de ésta.

Este patrón de emplazamiento industrial se aceleró al inicio del siglo XXI y, en paralelo, se construyeron nuevos desarrollos inmobiliarios, una construcción y ampliación de vías rápidas urbanas, mientras que las características del servicio del sistema de transporte público de pasajeros no evolucionaron mayormente.

Cabe mencionar que no existen carriles preferenciales para el transporte público, éstos se mezclan con el tráfico privado, compiten por el pasaje, no usan cívicamente los carriles de las vialidades (entrecruzamientos indiscriminados a lo largo del recorrido), e influyen la congestión tal como lo demostró Ramírez (2012) al emplear microsimulación de tráfico.

Respecto a los efectos en el gasto familiar en transporte, este artículo mostrará una primera aproximación, no obstante, requieren ser estudiados con más detalle. Los prestatarios del transporte público están constituidos en su mayoría en organizaciones. No obstante, como en muchas ciudades latinoamericanas, la propiedad y gestión que se presenta con los concesionarios corresponde a igual número de unidades, lo que indica que el esquema hombre-camión no ha evolucionado, afectando la rentabilidad y el servicio eficiente a la ciudadanía.

Transconsult (2004) expone que la forma de explotación hombre-camión ocasiona una serie de deficiencias que dificultan un adecuado desempeńo del sistema de transporte público en Querétaro y enumera los siguientes efectos: a) Disputa individualizada por el mercado donde cada individuo tiene como objetivo maximizar su utilidad; $b$ ) Nulo o bajo aprovechamiento de las economías de escala, gran parte de las compras de refacciones se hacen de manera individual; c) Fomento de la presencia de cotos de poder, donde los líderes sindicales y su gente son los beneficiados por las pequeñas economías de escala que se logran hacer; $d$ ) Ánimo a la corrupción en su relación más simple gobierno-líder sindical, pues no se da acceso a los individuos a los procesos de gestión; e) Excesivos costos de explotación en el sistema; $f$ ) Falta de seguridad laboral para los conductores, pues cada uno de ellos tiene una relación individual empleado-patrón, la mayoría de las veces sin cobertura de servicios de salud.

La demanda de pasajeros en el sistema de transporte público, según el Centro Queretano de Recursos Naturales (CQRN, 2003), se incrementa a una tasa anual de $2.1 \%$, tasa inferior al crecimiento poblacional; lo que indica, en principio, una mayor participación del transporte privado 
en la movilidad de Querétaro. Así, se observa un efecto indefectible en la modificación de la tasa de motorización y en el porcentaje de viajes en automóvil al tiempo que repercute en inhibición de movilidad no obligada de personas no propietarias y usuarias de automóviles.

\section{Metodología}

Molinero y Sánchez (2003) mencionan que la encuesta O-D permite obtener información actualizada sobre el número de viajes y la ubicación de las principales zonas atractoras y generadoras de éstos, así como predecir el comportamiento del usuario y las necesidades de desplazamiento de los habitantes; también clasifica sus necesidades con la finalidad de brindar un mejor servicio y conoce la demanda potencial, la atendida y la insatisfecha.

El tipo de muestra que se utilizó para la encuesta O-D en la zcQ fue estratificada, descrita por Picco et al. (2010) como la división de estratos de una población; en cada una de ellas los elementos deberán ser homogéneos respecto a las variables en estudio. Se toma una muestra de cada estrato, lo que aumenta la precisión de las estimaciones; es decir, ciertas variables independientes no serán aleatorias, por ejemplo un rango de ingreso (Ortúzar y Willumsen, 2008).

Se consideró como unidad básica geográfica de la subdivisión de la zCQ el Área Geoestadística Básica (Ageb), que es la unidad estadística territorial básica del Instituto Nacional de Geografía e Informática de México (INEgi, 20Io). En el caso en particular, es posible considerar que el interior de cada zona (Ageb) presenta características similares, de lo anterior se obtuvo la función para cada una, que nos ofrece la probabilidad de uso del medio de transporte en relación con el ingreso.

Se realizó la estimación a partir de un muestreo aleatorio simple con la fracción que le corresponde a cada estrato para cada subpoblación, tal como expone Ortúzar y Willumsen (2008). Se considera la totalidad de hogares en la zCQ y, siguiendo las recomendaciones de Bruton (1985), Secretaría de Desarrollo Social (Sedesol) (s.f.), Ibeas et al. (2007) y Ortúzar y Willumsen (2008), se obtuvieron 2,819 hogares a encuestar de un total de 156,600 , pues la población de la ZCQ, según los resultados del Censo Nacional de Vivienda del año 2010, es de 801,940 habitantes.

Así, se entrevistaron 1.5\% de los hogares (es decir 2,349), más 20\% (470) por cualquier tipo de error (Sedesol, s.f.), tal como no-respuestas, o algunos cometidos por los entrevistadores y la gente de campo; se distribuye la muestra a partir del número de hogares por Ageb.

Como advierten Ibeas et al. (2007) estamos en presencia de un trabajo con una muestra enorme y los problemas intrínsecos inducen a que en 
muchos organismos, especialmente en países en vías de desarrollo, se piense que estos tamańos son esenciales y que se requieren tamaños de hasta 20\% más grandes en la encuesta con el fin de afrontar pérdidas eventuales de validación, como lo sugiere Sedesol (s.f.).

El trabajo de campo se realizó con el apoyo de 125 alumnos de licenciatura y maestría de la Universidad Autónoma de Querétaro, entre noviembre del 2010 y febrero del 2011 (exceptuando el periodo vacacional de diciembre). El cuestionario se aplicó a individuos mayores de siete años preguntando a cada uno de ellos de manera individual sobre todos los desplazamientos que realizaron el día anterior con una duración en tiempo de viaje mayor a cinco minutos, y al jefa(e) de familia sobre de los principales desplazamientos de residentes ausentes en el momento de aplicar el cuestionario. Se encuestó de martes a sábado, siempre y cuando el día anterior no hubiese sido festivo o se presentara un fenómeno natural que modificara los patrones de viajes.

Así, se obtuvo información de las características socioeconómicas de cada uno de los miembros del hogar, preferencias reveladas tales como el medio utilizado en los viajes realizados y su motivo, completando con características como el tiempo invertido en cada uno de ellos, tiempos de espera en parada para transporte público, evaluaciones de las características de la movilidad, entre otros, y preferencias declaradas, así como por ejemplo en el caso de los no usuarios de transporte público si lo utilizarían si es que mejorara la calidad del servicio, y a los no usuarios de bicicleta su preferencia para emplear dicho medio en caso de mejoras en infraestructura exclusiva. La zona de estudio comprendió 331 Ageb.

Para lograr el objetivo del presente artículo se empleó estadística descriptiva para explicar, entre otras, las siguientes variables: las características socioeconómicas de los usuarios de cada medio de transporte, el tiempo empleado en sus viajes, número de viajes, motivos. A la vez, se emplearon regresiones lineales para determinar relación entre valoración del sistema y las características socioeconómicas de los individuos. A partir de preguntas sobre la valoración del servicio de transporte público se analizaron los parámetros de calidad del servicio, tomando como base el análisis de Sánchez y Romero (2010). Por último, se realizaron nueve modelos logit de respuesta binaria para determinar la influencia de características socioeconómicas en la elección de medios de transporte.

Es necesario definir algunos parámetros para que el lector internacional comprenda el contexto. El primero es el tipo de cambio de pesos de los Estados Unidos Mexicanos (MXP) a dólares de los Estados Unidos de América (USD), se calculó al año de la investigación empleando el promedio del 2010 a partir de los datos publicados por el CEFP (2013) y determinados por el Banco de México, el resultado fue de 12.636 pesos 
mexicanos por dólar. El segundo, el salario mínimo diario en la región de estudio (C) de 54.47 pesos mexicanos (4.31 dólares) en el año 2010.

\section{Resultados y discusión}

En esta sección se presentan los resultados socioeconómicos obtenidos de la aplicación de la encuesta en la zCQ, los desplazamientos, medios y motivos, la valoración de las condiciones actuales de la movilidad, las características de los viajes en vehículos motorizados y en medios no motorizados, un análisis comparativo sobre las perspectivas para la transferencia del transporte privado al público y finalmente, una serie de modelos de elección discreta que sostienen la primer hipótesis de esta investigación.

\subsection{Resultados socioeconómicos}

Antes de mostrar los resultados detallados de la encuesta O-D, cabe mencionar que el género y el número de viviendas con vehículo obtenidos en la encuesta fueron contrastados con los resultados del censo del año 2010 reportados por el INEGI con el fin de validar la información recabada, se obtuvo una diferencia del $0.5 \%$ en el género ( $49 \%$ de hombres, el INEGI reporta $48.5 \%$ ) y de $0.47 \%$ en el número de viviendas con vehículo (se obtuvo $65.47 \%$ y el INEGI reporta $65 \%$ ). Entre la información obtenida se destaca que $28.47 \%$ de los residentes de la zCQ tienen un ingreso de hasta dos salarios mínimos diarios (SMD); $32.33 \%$ de más de dos a cuatro y $39.2 \%$ de más de cuatro SMD. De los encuestados, $57.24 \%$ reportaron percibir un ingreso económico y $28.33 \%$ presenta un nivel máximo de estudios terminados de bachillerato, $24.85 \%$ de licenciatura y $23.3 \%$ de secundaria.

\subsection{Desplazamientos, medios y motivos}

El porcentaje de empleo de los medios de transporte, respecto a todos los desplazamientos realizados en la zCQ, se reparte de la siguiente manera: en autobús público $38.5 \%$, automóvil (conductor) $36.34 \%$, a pie $11.53 \%$, automóvil (acompañante) 8.59\%, automóvil rentado-taxi 2.02\%, autobús de empresa $0.99 \%$, motocicleta $0.97 \%$, bicicleta $0.72 \%$, autobús escolar $0.39 \%$, y otro medio $0.04 \%$.

Ello muestra que en el área de estudio $47.92 \%$ de los desplazamientos se hace en automóvil, taxi y motocicleta, en $39.88 \%$ se emplea un medio de transporte masivo, y $12.25 \%$ un medio no motorizado. La tasa media de desplazamientos es de 2.44 viajes diarios por individuo al día, alrede- 
dor de 1,032,000 desplazamientos diarios; el tiempo promedio empleado es de 27.64 minutos.

El motivo de los viajes en un día típico laboral se reparte de la siguiente manera: $18.13 \%$ trabaja en el sector servicios, $12.09 \%$ asistir a la escuela, $5.66 \%$ compras, $4.42 \%$ asuntos personales, $3.35 \%$ trabajo en el sector industria, $2.31 \%$ acompañar personas, $2.3 \%$ recreación, $1.78 \%$ ir a comer, $1.62 \%$ relacionado con el trabajo, $0.99 \%$ de salud, $0.73 \%$ trabajo en el sector primario, $0.45 \%$ practicar deporte, $2.12 \%$ otro motivo y $44.04 \%$ para regresar al hogar. En cuanto al número de desplazamientos diarios, la población muestra la siguiente distribución: de los individuos, $79.19 \%$ realizan dos viajes diarios, $19.49 \%$ tres y cuatro viajes, $4.12 \%$ entre cinco y nueve desplazamientos, y más de diez viajes $0.21 \%$.

\subsection{Valoración de las condiciones actuales de la movilidad en la ZCQ}

Estado de la infraestructura: una parte del cuestionario se enfocó a que los entrevistados valoraran algunas condiciones y costos referentes al transporte en la zCQ. En este sentido, el primer punto se encauzó a que la población valorara las condiciones actuales de movilidad en la zona; al respecto, el entrevistador pedía al entrevistado que valorara el estado de la infraestructura vial, acceso a los sistemas de transporte, entre otros. Las respuestas fueron las siguientes: muy malas, 17.05\%; malas, 9.67\%; aceptables, 44.08\%; buenas, $22.94 \%$; y muy buenas, $6.26 \%$.

Nivel tarifario: un segundo punto se dirigió a la tarifa del billete de transporte, se les preguntó cuál consideran que es la tarifa adecuada para un buen sistema de transporte público (es decir, moderno y eficiente), las respuestas del total de la población encuestada: menos de 4 pesos, $12.38 \%$; entre $\$ 4$ y $\$ 4.99,29.78 \%$; entre $\$ 5$ y $\$ 5.99,35.91 \%$; entre $\$ 6$ y $\$ 6.99$, $12.5 \%$; más de $\$ 7,5.82 \%$; y $2.99 \%$ no sabía cual sería la tarifa adecuada.

Transbordos: el tercer punto se relacionó a la incursión de transbordos en una misma tarifa del billete de transporte. Se les preguntó cuánto estarían dispuestos a pagar para llegar a su destino pudiendo utilizar varias líneas de transporte, las respuestas del total de la población encuestada fueron: menos de $\$ 4,3.99 \%$; entre $\$ 4$ y $\$ 4.99,12.98 \%$; entre $\$ 5$ y $\$ 5.99$, $20.89 \%$; entre $\$ 6$ y $\$ 6.99,18.8 \%$; más de $\$ 7,34.56 \%$; y $8.01 \%$ no sabía cual sería la tarifa adecuada.

\subsection{Características de los viajes en vehículos motorizados}

Respecto a las características socioeconómicas de los usuarios del vehículo privado se destaca un alto porcentaje de varones (77.5\%), un nivel medio y alto de ingreso ( $69 \%$ con un ingreso de cuatro y más SMD), $84.22 \%$ de los usuarios es el jefe(a) de familia y $87.91 \%$ percibe salario. 
En cuanto al nivel de estudios, las tasas más altas reportadas fueron de $40.98 \%$ con estudios terminados de licenciatura, $21.62 \%$ de bachillerato y $15.38 \%$ de secundaria.

En cuanto a las principales ocupaciones de los usuarios, $27.5 \%$ son empleados, $22.94 \%$ profesionistas y $10.44 \%$ comerciantes. Respecto al número de desplazamientos, $67.53 \%$ de los individuos realizan dos viajes diarios, $24.59 \%$ tres y cuatro viajes, y 7.88\% más de cinco desplazamientos, el máximo reportado fueron diez.

Si bien hay interés en los usuarios del vehículo privado en emplear el transporte público (véase apartado 4.6.1.), la gráfica IV muestra porqué los usuarios del vehículo privado no utilizan el transporte público. Al eliminar a los usuarios de vehículo privado que no están interesados en utilizar el transporte público (TР) se puede clasificar la responsabilidad del prestatario, de la autoridad reguladora, o de ambos como factor de disuasión en el uso del TP.

Prestatarios: responsables del trato al usuario, forma de manejo, estado físico del autobús, acceso a discapacitados y la comodidad, es responsable de que $65.3 \%$ de los usuarios potenciales no empleen el TP. Si bien algunos de estos puntos están regulados directamente por el Estado a través de los títulos de concesión, los vicios en la evaluación del sistema incitan a su incumplimiento.

Autoridad reguladora: tiene responsabilidad en la cobertura del sistema y en los tiempos de trayecto, afectan en $30.7 \%$ la disuasión en su uso. Un punto que directamente ambos sectores gestionan es la tarifa del sistema y tiene un impacto directo en $4 \%$. Respecto a este último punto, en esta investigación se realizó un análisis de costos de operación para determinar la tarifa técnica del billete de transporte público. Dicho estudio tomó como referencia a la empresa mejor organizada del sistema.

Antecedentes con los cuales coincidimos son expuestos por Transconsult (2004), que menciona que la tarifa de Querétaro es una de las más elevadas de México, producto de una sobreoferta de unidades que ocasiona bajos niveles de captación y de utilización de los vehículos. Se está hablando de una tarifa plana de 6.50 pesos mexicanos por realizar un viaje en una unidad, pues el billete no incluye transbordos. El costo técnico de la tarifa sin utilidad ni impuestos obtenido por esta investigación a partir del procedimiento recomendado por Molinero y Sánchez (2003) fue de 3.99 pesos mexicanos a costos del año 2010.

También se obtuvo respuesta sobre dónde los usuarios de automóvil aparcan sus vehículos; $19.94 \%$ lo hacen en un aparcamiento público, $38.20 \%$ en un privado, $40.92 \%$ en la vía pública y $0.74 \%$ en un espacio diferente. El plano I, parte a, muestra los orígenes y destinos de los viajes en las Ageb de la ZCQ en la hora de máxima producción de viajes, entre las 7:00 y 8:00 h, (gráfica I) se observa que aún con su reciente expansión 


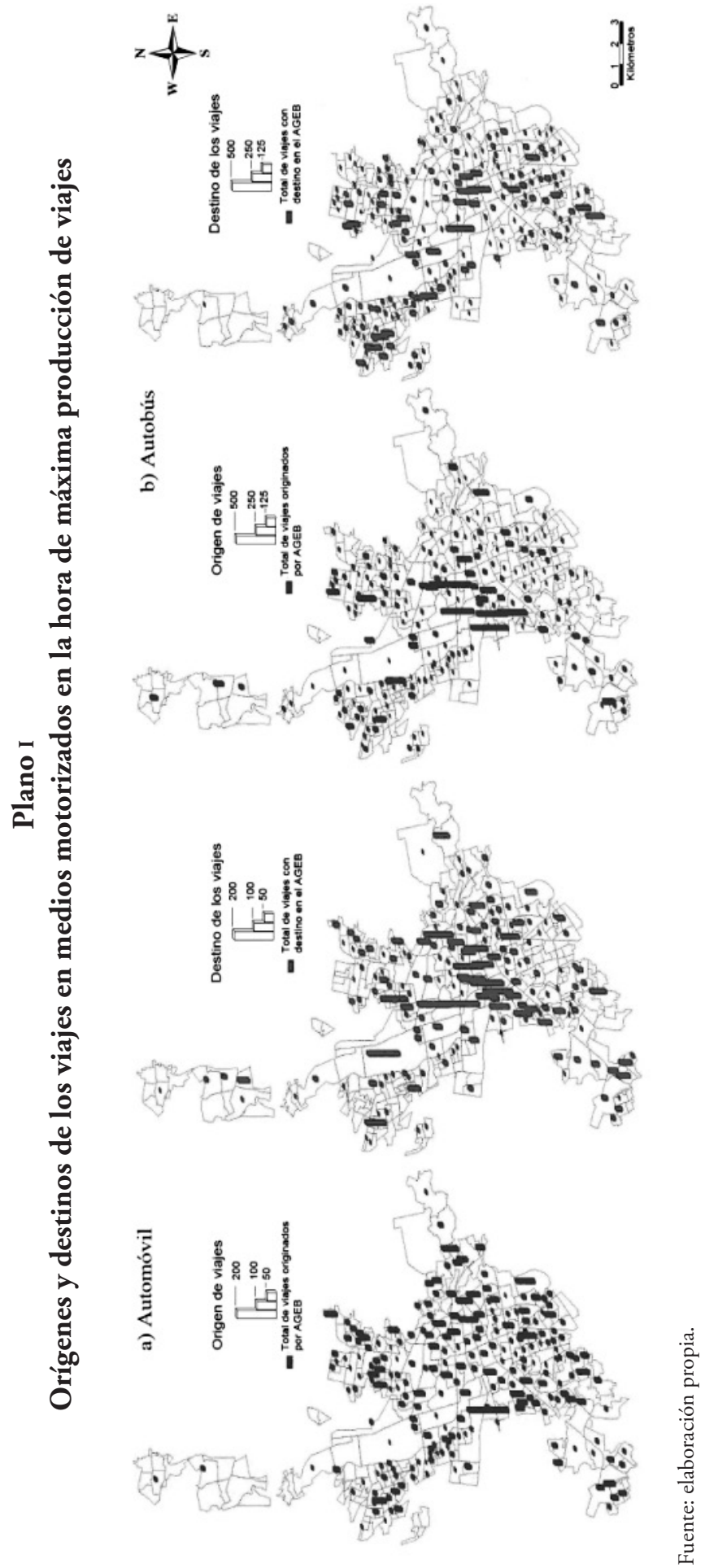




\section{Gráfica I}

\section{Histograma de producción de viajes}

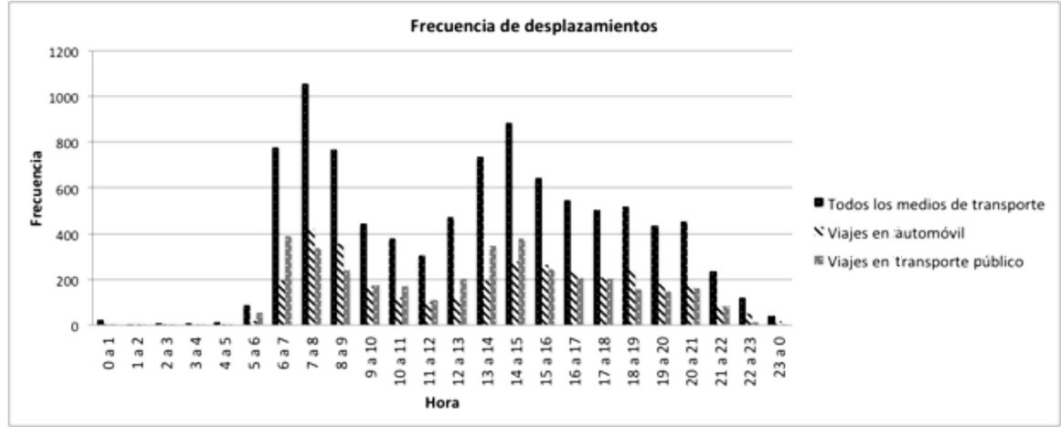

Fuente: elaboración propia.

\section{Plano II}

Valores medios del suelo por Ageb

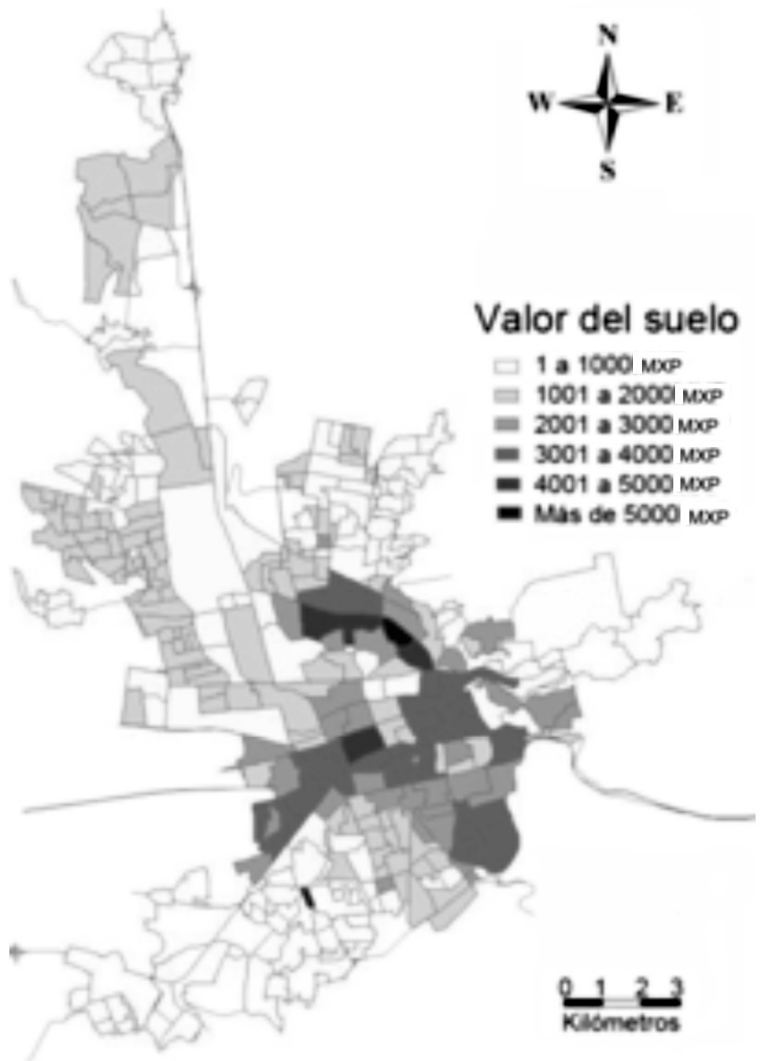

Fuente: elaboración propia. 


\section{Gráfica II \\ Relación entre el valor medio del suelo por Ageb y empleo de medio de transporte}

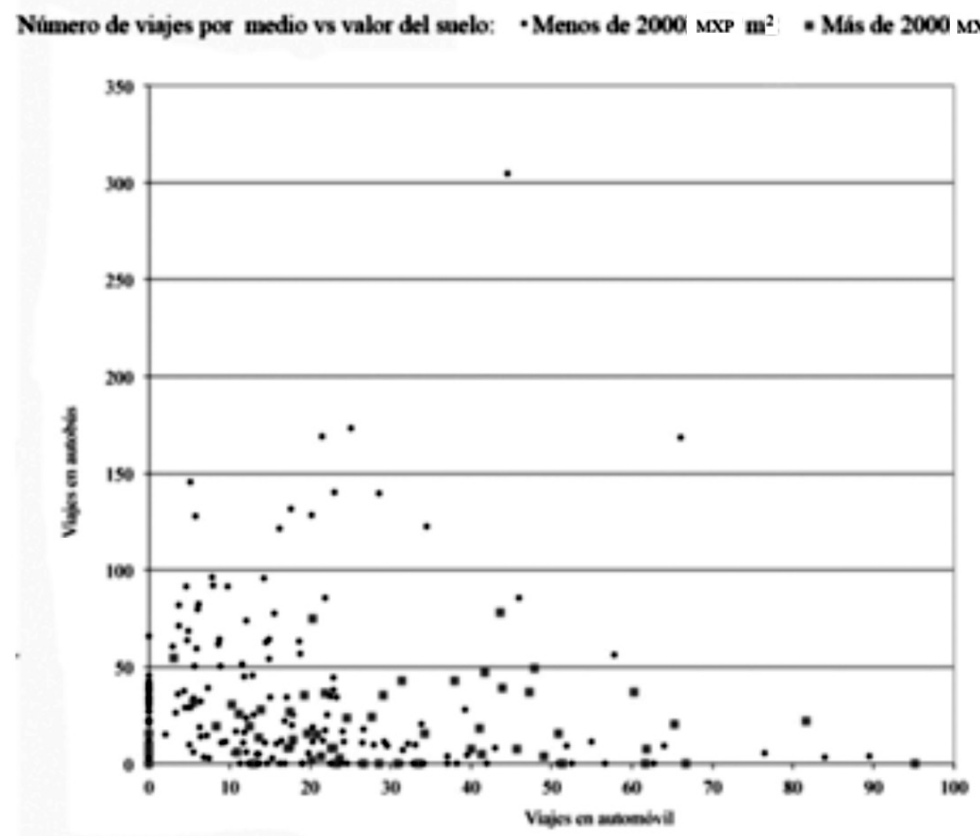

Fuente: elaboración propia.

y dispersión continúa siendo una ciudad relativamente monocéntrica en los destinos de las actividades, y si se relacionan orígenes de los viajes se confirma la relación de uso de este medio con los valores medios y altos de suelo, tal como se muestra en el plano ir y gráfica II.

Respecto a las características socioeconómicas de los usuarios del transporte público se destaca un mayor porcentaje de mujeres $(51.28 \%$ de los usuarios) y un bajo ingreso económico (68.63\% con ingresos menores a cuatro SMD), $61.72 \%$ de los usuarios es el jefe(a) de familia y $63.8 \%$ percibe salario.

En cuanto al nivel de estudios, las tasas más altas reportadas fueron de $31.78 \%$ con estudios terminados de secundaria, $26.65 \%$ de bachillerato y $15.57 \%$ de licenciatura. En cuanto a las principales ocupaciones de los usuarios, el $27.32 \%$ son empleados, $19.7 \%$ se dedica al hogar y $12.58 \%$ son estudiantes, como actividad principal. Los tiempos de viaje en vehículo se muestran en la gráfica viI.

Los tiempos de camino a la parada de autobús se distribuyen de la siguiente forma: hasta dos minutos, 6.99\%; de dos a cuatro minutos, $19.56 \%$; de cuatro a seis minutos, $46.18 \%$; de seis a ocho minutos, $1.78 \%$; 
de ocho a 10 minutos, $0.82 \%$; de 10 a 15 minutos, $19.08 \%$; de 15 a 20 minutos el 3.65\%; y $1.95 \%$ más de 20 minutos. En lo que concierne a los intervalos entre unidades, éstos son breves, en este sentido Transconsult (2004) expone que la frecuencia media es de 12.4 unidades en la hora de máxima demanda. Los tiempos de espera en la parada reportados son los siguientes: $45.03 \%$ de los usuarios de transporte público espera en la parada hasta cinco minutos, el $33.94 \%$ hasta 10 minutos, el $14.68 \%$ hasta 15 minutos, el $4.4 \%$ hasta 20 y el $1.96 \%$ más de 20 minutos.

Esta intensidad en la prestación del servicio de transporte en los principales corredores de la ciudad ha favorecido de manera importante a los usuarios en términos de tiempos de espera; sin embargo, influye en el encarecimiento del servicio por la baja ocupación en las unidades mencionada anteriormente; además de influir en el congestionamiento por la misma presencia de las unidades de TP y en una mayor emisión de gases contaminantes. En cuanto al número de viajes $81.5 \%$ de los usuarios de TP realizan dos viajes diarios; $15.83 \%$ tres y cuatro viajes; y $1.67 \%$ más de cinco desplazamientos, el máximo reportado fueron siete.

Los usuarios del servicio de TP valoraron la comodidad a bordo de las unidades, sus respuestas fueron las siguientes: muy mala, 15.7\%; mala, 12.4\%; aceptable, 39.53\%; buena, 27.72\%; y muy buena, $4.65 \%$. Se realizaron regresiones con el fin de demostrar si la percepción en la valoración de la comodidad tiene correlación con las variables tales como el grado de educación y el ingreso, siendo el grado de educación el único coeficiente estadísticamente significativo. El signo negativo en la ecuación nos refleja el efecto que tiene un mayor grado de educación respecto a una expectativa de comodidad, la regresión obtenida es la siguiente:

Comodidad = $5.76-0.147$ grado de educación

$\begin{array}{lrrcc}\text { Predictor } & \text { Coeficiente } & \text { SE Coef } & \mathrm{T} & \mathrm{P} \\ \text { Constante } & 5.7617 & 0.2875 & 20.04 & 0.000 \\ \text { Grado de educación } & -0.14714 & 0.06832 & -2.15 & 0.032\end{array}$

Se les pidió a los usuarios de TP que valoraran la seguridad del servicio, sus respuestas fueron las siguientes: muy mala, 18.99\%; mala, 15.51\%; aceptable, 33.72\%; buena, 24.23\%; y muy buena, 7.56\%. Otra solicitud fue que valoraran el tiempo de viaje a bordo de las unidades, sus respuestas fueron las siguientes: muy malo, 12.82\%; malo, 12.24\%; aceptable, $34.76 \%$; bueno, $33.01 \%$; y muy bueno, $7.19 \%$. Respecto a la seguridad y la valoración del tiempo de viaje no se encontró un coeficiente estadísticamente significativo, como fue en el caso de la comodidad. 
Respecto a la tarifa del billete de transporte se les preguntó cuál consideraban que era la adecuada para un buen sistema de transporte público (es decir, moderno y eficiente), en el mismo sentido, se incluyó otra pregunta relacionada a la incursión de transbordos en una misma tarifa del billete de transporte (¿cuánto estarían dispuestos a pagar para llegar a su destino pudiendo utilizar varias líneas de transporte?), las respuestas a estas dos preguntas se muestran en las gráficas $v$ y vi. No obstante, debido a la cobertura y número de unidades que sirve a la ciudad, el porcentaje de usuarios que requiere de transbordos es bajo actualmente, de esto se hablará a continuación.

Existen dos tarifas en el transporte público, la preferencial que se le aplica a estudiantes de nivel medio y superior, adultos mayores y personas con discapacidad con un costo de 3.50 pesos mexicanos, y la normal para el resto de la población. De los viajes realizados en transporte público, $13.9 \%$ fueron sufragados mediante tarifa preferencial, de los cuales, $5.2 \%$ de dichos usuarios requirió realizar un trasbordo efectuando nuevamente el pago. $86.1 \%$ fue realizado con tarifa normal, $6 \%$ de los cuales realizó trasbordo.

$\mathrm{Al}$ considerar que $22.25 \%$ de los usuarios de transporte se encuentran en el rango de edad entre 15 y 25 años (edad normal de estudio del nivel medio y superior), la investigación arrojó que sólo $28.3 \%$ de los individuos en dicho rango de edad reportó pagar con tarifa preferencial. El plano I, parte $b$, muestra los orígenes y destinos de los viajes en transporte público en las Ageb de la ZCQ en la hora de máxima demanda para este medio de transporte (entre las 14:00 y 15:00 h), al igual que en vehículo privado se observa el centralismo, y al relacionar con el plano II los destinos de los viajes, se nos confirma, a partir de los orígenes, que los individuos que emplean este medio de transporte residen en zonas de bajo valor de suelo.

\subsection{Viajes en medios no motorizados}

Respecto a las características socioeconómicas de los individuos que se desplazan principalmente a pie, las mujeres son las que realizan el mayor porcentaje de desplazamientos $(52.22 \%)$, por edad, se observa un mayor uso de este medio en individuos entre 10 y 30 años (48.9\%), lo que corrobora que los usuarios dentro del entorno domiciliario son, en su mayoría, hijo(a)s (46.56\%). Los desplazamientos a pie son realizados principalmente por personas de bajos ingresos $(59.31 \%$ percibe hasta dos salarios mínimos diarios) y dependientes (el $72.86 \%$ ), en cuanto a la ocupación principal, $48.09 \%$ de los desplazamientos los efectúan indivi- 
duos quienes realizan algún tipo de estudio, y $22.65 \%$ individuos se dedican al hogar.

El grado máximo de estudios concluidos de los reportados fue secundaria (con $31.38 \%$ ), bachillerato (con 28.06\%) y primaria (con $18.88 \%$ ). En cuanto al número de desplazamientos, $79.84 \%$ de los individuos realizan dos viajes diarios, $14.13 \%$ tres y cuatro viajes, y $6.03 \%$ más de cinco desplazamientos, el máximo reportado fueron doce. Los principales motivos de del viaje son los siguientes: $44.53 \%$ del total de los desplazamientos son para ir a la escuela, $16.06 \%$ trabajo en el sector servicios, $15.33 \%$ de compras, $5.6 \%$ de regreso a casa, y $4.38 \%$ acompañar a otra persona.

En el plano III, parte a, se muestran las líneas de deseo de los desplazamientos a pie con una duración mayor a cinco minutos y con zona origen-destino diferente (del total de los viajes reportados a pie, $35 \%$ son intrazonales), se observa la concentración en la principal zona universitaria de la región (zU), además cómo estos viajes se encuentran concentrados en cuatro zonas bien diferenciadas, incluido el centro de la ciudad (zC), por las principales arterias viales que influyen en cierta medida a la no permeabilidad del territorio (Junyent, 2001, desarrolla una investigación que aborda a detalle el tema del efecto barrera inducido por los corredores viarios).

En cuanto a las características socioeconómicas de los usuarios de bicicleta, la mayoría de los desplazamientos son efectuados por varones (70.83\%) e individuos entre 20 y 30 ańos (54.16\%). Respecto al ingreso, son realizados principalmente por personas con bajo ingreso económico (64.29\% con ingreso diario de hasta cuatro SMD), los cuales, en su mayoría, perciben salario (70.83\%). De los viajes, $25 \%$ son efectuados por individuos que realizan estudios y $25 \%$ por empleados. El grado máximo de estudios concluidos de los reportados fue bachillerato (29.17\%), licenciatura $(25 \%)$ y primaria $(24.99 \%)$.

En cuanto al número de desplazamientos, $69.57 \%$ de los individuos realizan dos viajes diarios, $17.39 \%$ tres y cuatro viajes, y el 13.05\% más de cinco desplazamientos, el máximo reportado fueron ocho. En este medio, como en el automóvil, lógicamente es empleado el encadenamiento, pues en $44 \%$ de los viajes el motivo fue regresar a casa. Los individuos que se desplazan en bicicleta exponen que no emplean el тP por los siguientes motivos: a $11 \%$ no le interesa, $0 \%$ por la tarifa, $11 \%$ mencionó que la parada le queda lejos, $22 \%$ por el trato al usuario y forma de manejo, el $0 \%$ por el estado físico del autobús, $22 \%$ por los tiempos de trayecto y $22 \%$ por la comodidad.

El plano III, parte b, refleja las líneas de deseo de los desplazamientos en bicicleta, se observa atracción hacia las zonas industriales (zI) y uni- 


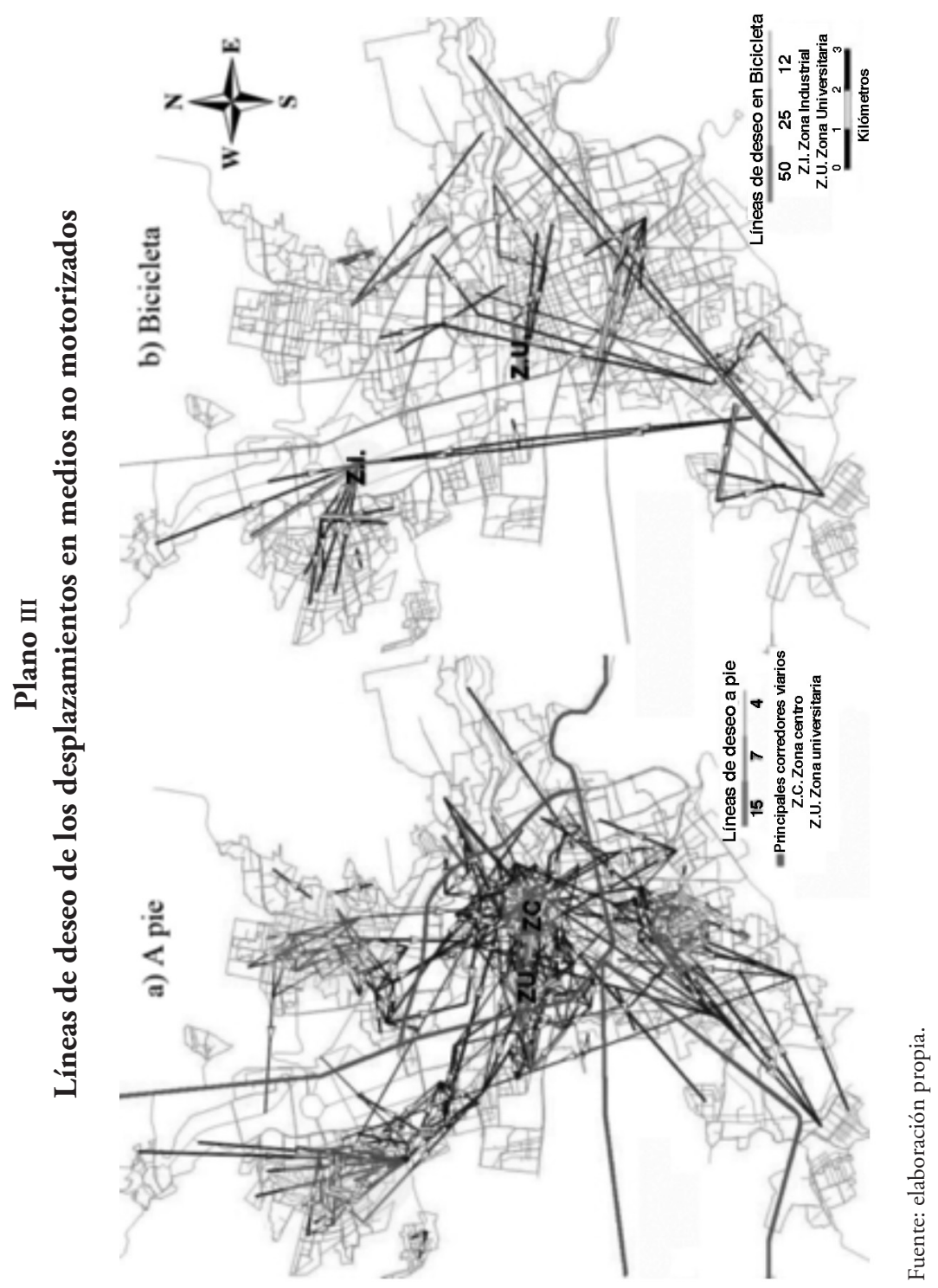


versitarias (zu) y en cierto grado hacia el centro de la ciudad. En su mayoría no son desplazamientos que rebasen los cuatro kilómetros de longitud.

\subsection{Análisis comparativo: perspectivas para la transferencia del transporte privado al público}

\subsubsection{Comparación de percepciones entre los usuarios de los diferentes medios de transporte}

En este apartado se compararán las diferentes percepciones dependiendo del medio de transporte empleado en los desplazamientos. La gráfica III muestra el porcentaje de respuestas referentes a la valoración de la movilidad en la zCQ dependiendo del medio de transporte que emplea el individuo. Se observa que los usuarios de Tp tienen una mayor percepción negativa de las condiciones para desplazarse en la ciudad. En el cuestionario se evaluaba a través de un puntaje de cero a nueve, resulta que $66.47 \%$ expuso una nota entre cero y cinco a las condiciones para desplazarse.

\section{Gráfica III}

Valoración de las condiciones para desplazarse en la ZCQ

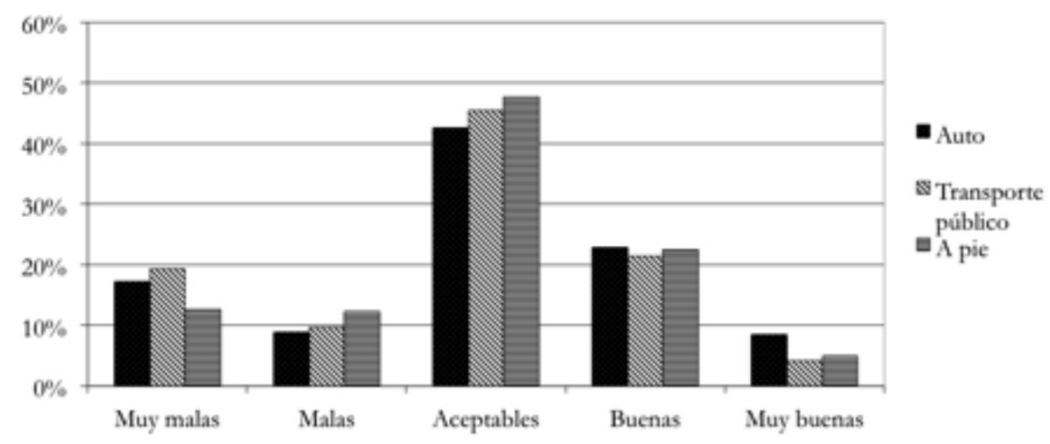

Fuente: elaboración propia.

Al comparar a los usuarios de automóvil con los que se desplazan a pie, respecto al principal motivo por el cual no se emplea el transporte público (gráfica IV), se observa un alto porcentaje de usuarios de automóvil que no les interesa el TP, mientras que a los viajeros a pie perciben como principal disuasor el trato al usuario y el costo del viaje (como ya se mencionó, estos individuos muestran un menor ingreso respecto a los usuarios de automóvil). Ahora bien, los usuarios de vehículo privado expresan la comodidad y el tiempo de viaje como principales disuasores. 


\section{Gráfica IV \\ Motivo por el cuál no se emplea el TP}

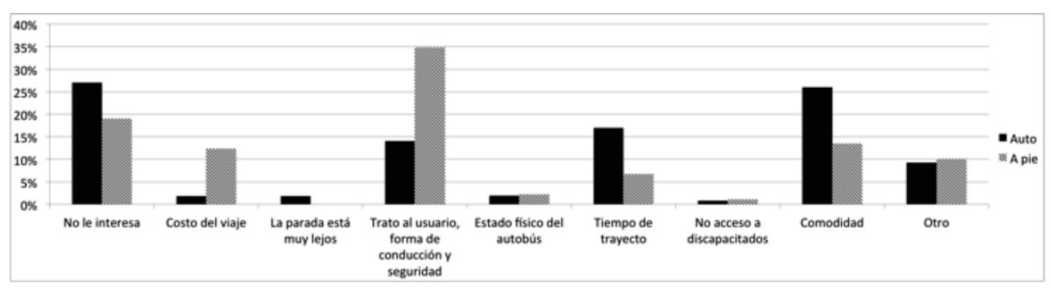

Fuente: elaboración propia.

Se preguntó si emplearían el TP en caso de que dicho servicio mejorara, es decir, un servicio moderno, eficiente, con buen trato, mejores tiempos de viaje, entre otros. De los usuarios de automóvil, $41.61 \%$ respondieron que sí, y $30.1 \%$ respondieron no, el restante $28.29 \%$ no sabía. Respecto a los que realizan viajes a pie, $53.4 \%$ respondió sí, el $19.42 \%$ no y el $27.18 \%$ no sabía. Por lo anterior, se observa que los individuos que realizan desplazamientos a pie muestran un mayor interés en emplear el transporte público en relación con los usuarios de automóvil.

Asimismo, se preguntó a la población en general la tarifa que considerarían adecuada para un buen sistema de TP. En este sentido, se observa un comportamiento congruente con el Principio de Pareto, donde alrededor de $80 \%$ de los usuarios de los tres medios expuestos en la gráfica $v$, consideran que deberá ser menor a seis pesos mexicanos. La gráfica VI expone el resultado de integrar trasbordo en el costo del billete, el estudio muestra que alrededor de $60 \%$ de los usuarios de los tres medios consideran que debería ser inferior a siete pesos mexicanos. Hay que recordar que sólo en $5.7 \%$ de todos los desplazamientos realizados en TP fue necesario trasbordar.

Respecto a los tiempos de viaje en los medios motorizados, los usuarios de vehículo privado emplean menores tiempos para llegar a su destino, pues el $56.85 \%$ de los usuarios consume hasta 30 minutos (gráfica VII), mientras que en тP, $48.1 \%$ de los desplazamientos consumen dicho tiempo; ahora bien, si incluimos el tiempo de camino y espera en la parada, sólo $21.54 \%$ de los desplazamientos son realizados en un tiempo inferior a 30 minutos. Lo anterior explica porqué el tiempo de viaje en TP es una de las principales variables disuasoras para su empleo.

La zona marcada en el recuadro de la gráfica vil conforma una transición en el desequilibrio de los modos de transporte, al observarse que se acentúa el uso del transporte privado al incrementarse el tiempo total de traslado en transporte público. 


\section{Gráfica V}

Estimación de la tarifa adecuada para un buen sistema de TP

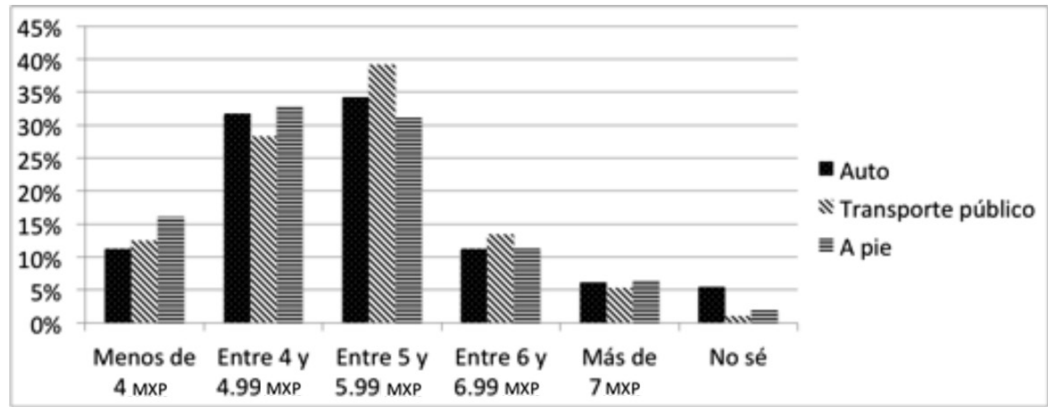

Fuente: elaboración propia.

\section{Gráfica VI}

Estimación de la tarifa adecuada para un sistema de TP con transbordo

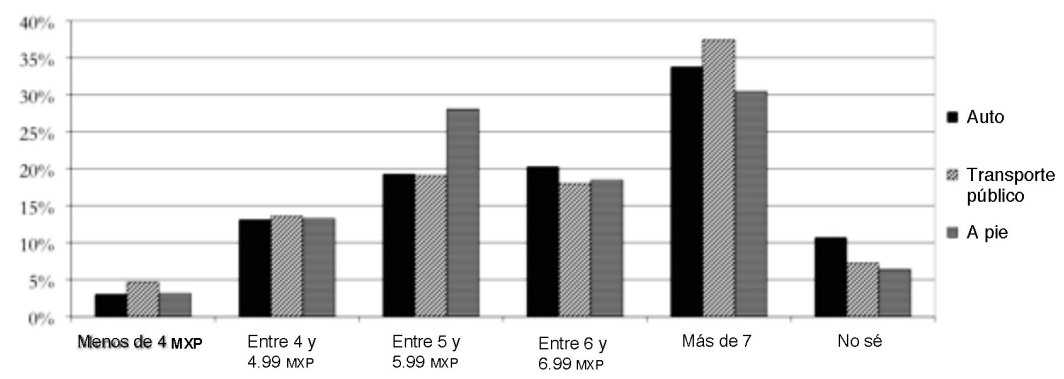

Fuente: elaboración propia.

\section{Gráfica VII}

Tiempos de viaje en los medios motorizados

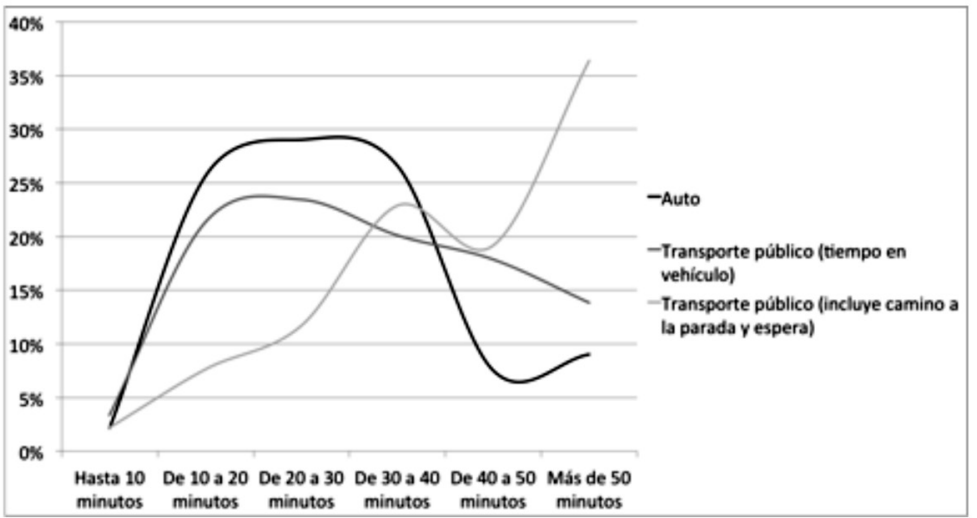

Fuente: elaboración propia. 
4.6.2. Los usuarios cautivos: el gasto en transporte como porcentaje del ingreso de los usuarios de transporte público

Al observar que los usuarios de transporte público presentan, en su mayoría, bajos ingresos, esta investigación se enfocó en analizar qué porcentaje de su ingreso lo invierten en transporte; el cuadro 1 muestra el número de viajes diarios realizados en TP respecto al ingreso de los individuos. Si recordamos que $68.63 \%$ de los usuarios de TP tienen un ingreso de hasta cuatro SMD.

La gráfica VIII muestra el porcentaje de salario empleado en transporte, a partir de ello se observa que en su mayoría las personas con menor ingreso invierten en su mayoría $23.87 \%$ de su ingreso en transporte; cabe mencionar que un gran porcentaje de estos individuos son dependientes, mientras que los individuos con más de dos y hasta cuatro salarios mínimos en su mayoría ya perciben salario y dichos individuos invierten en su mayoría el $7.96 \%$ de sus ingresos para poder acceder al mercado laboral. Algunos de estos individuos sustentan hogares, por lo cual el gasto familiar destinado al transporte se incrementa. Esta investigación no pretende ahondar en dicha línea pues es tema de investigación futura.

\section{Cuadro 1}

Ingreso y número de viajes diarios realizados en transporte público

\begin{tabular}{lrrrrrrr}
\hline $\begin{array}{l}\text { Viajes } \\
\text { salario }\end{array}$ & $\begin{array}{c}\text { Hasta un } \\
\text { salario } \\
\text { minimo }\end{array}$ & $\begin{array}{c}\text { Más de } \\
\text { uno a dos }\end{array}$ & $\begin{array}{c}\text { Más de } \\
\text { dos a } \\
\text { cuatro }\end{array}$ & $\begin{array}{c}\text { Más de } \\
\text { cuatro a } \\
\text { seis }\end{array}$ & $\begin{array}{c}\text { Más de } \\
\text { seis a } \\
\text { ocho }\end{array}$ & $\begin{array}{c}\text { Más de } \\
\text { ocho a } \\
\text { diez }\end{array}$ & $\begin{array}{c}\text { Más de } \\
\text { diez }\end{array}$ \\
\hline 2 & $89.18 \%$ & $85.71 \%$ & $87.82 \%$ & $81.94 \%$ & $88.89 \%$ & $87.50 \%$ & $71.71 \%$ \\
3 & $5.19 \%$ & $4.76 \%$ & $4.62 \%$ & $6.25 \%$ & $3.70 \%$ & $0.00 \%$ & $14.29 \%$ \\
4 & $3.46 \%$ & $8.47 \%$ & $6.30 \%$ & $10.42 \%$ & $4.94 \%$ & $8.33 \%$ & $14.00 \%$ \\
5 & $1.73 \%$ & $0.53 \%$ & $0.63 \%$ & $0.00 \%$ & $0.00 \%$ & $4.17 \%$ & $0.00 \%$ \\
6 & $0.44 \%$ & $0.53 \%$ & $0.21 \%$ & $1.39 \%$ & $2.47 \%$ & $0.00 \%$ & $0.00 \%$ \\
7 & $0.00 \%$ & $0.00 \%$ & $0.21 \%$ & $0.00 \%$ & $0.00 \%$ & $0.00 \%$ & $0.00 \%$ \\
8 & $0.00 \%$ & $0.00 \%$ & $0.21 \%$ & $0.00 \%$ & $0.00 \%$ & $0.00 \%$ & $0.00 \%$ \\
\hline
\end{tabular}

Fuente: elaboración propia.

\subsection{Modelación de preferencias}

A continuación se presenta una serie de modelos logit binarios con la finalidad de determinar las características individuales que mejor representan la atractividad de la alternativa elegida por los individuos. Ortúzar y Willumsen (2008: 334) mencionan que los modelos de elección discreta 


\section{Gráfica VIII}

\section{Porcentaje de salario empleado en transporte}

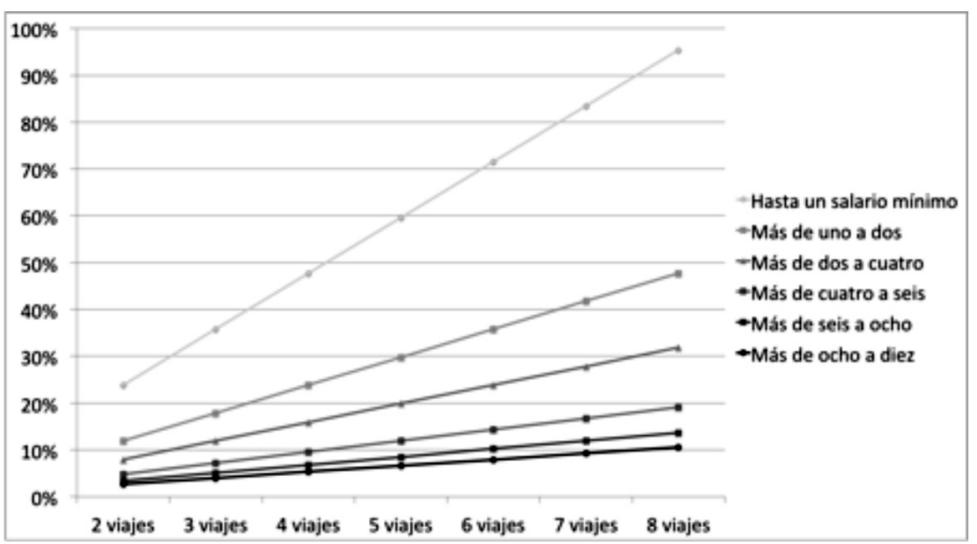

Fuente: elaboración propia.

afirman que "la probabilidad de que los individuos elijan una determinada alternativa es función de sus características socioeconómicas y de la relativa atractividad de la alternativa. Para representar la atractividad de la alternativa se utiliza el concepto de utilidad (artificio teórico convenientemente definido en forma tautológica como lo que el individuo intenta maximizar)". Cada variable representa un atributo de la alternativa o del viajero, en tanto que los coeficientes representan la influencia relativa de cada atributo, es decir, la contribución que cada variable aporta a la satisfacción total producida por cada alternativa. Así, los modelos estimados (cuadro 2) auxiliarán en la comprobación de las hipótesis de partida, reafirmando lo analizado en los puntos anteriores con el uso de estadística descriptiva.

\subsubsection{Entre el automóvil y el transporte público}

Se estimó un modelo logit de respuesta binaria para determinar qué parámetros son estadísticamente significativos en la elección del automóvil (4) y el transporte público (1). El modelo 1 del cuadro 2 muestra los coeficientes que resultaron estadísticamente significativos. La parte sistemática del modelo está conformada por el ingreso semanal y el tiempo de viaje dentro del vehículo, la constante del modelo es de -1.86. El cociente entre los partworths (coeficientes en la utilidad) de ingreso y tiempo está alrededor de 0.028 . El ingreso tiene un impacto de 34 veces el tiempo de viaje en el vehículo, lo que reafirma lo expuesto anteriormente en referencia a que los usuarios de automóvil presentan mayores ingresos 


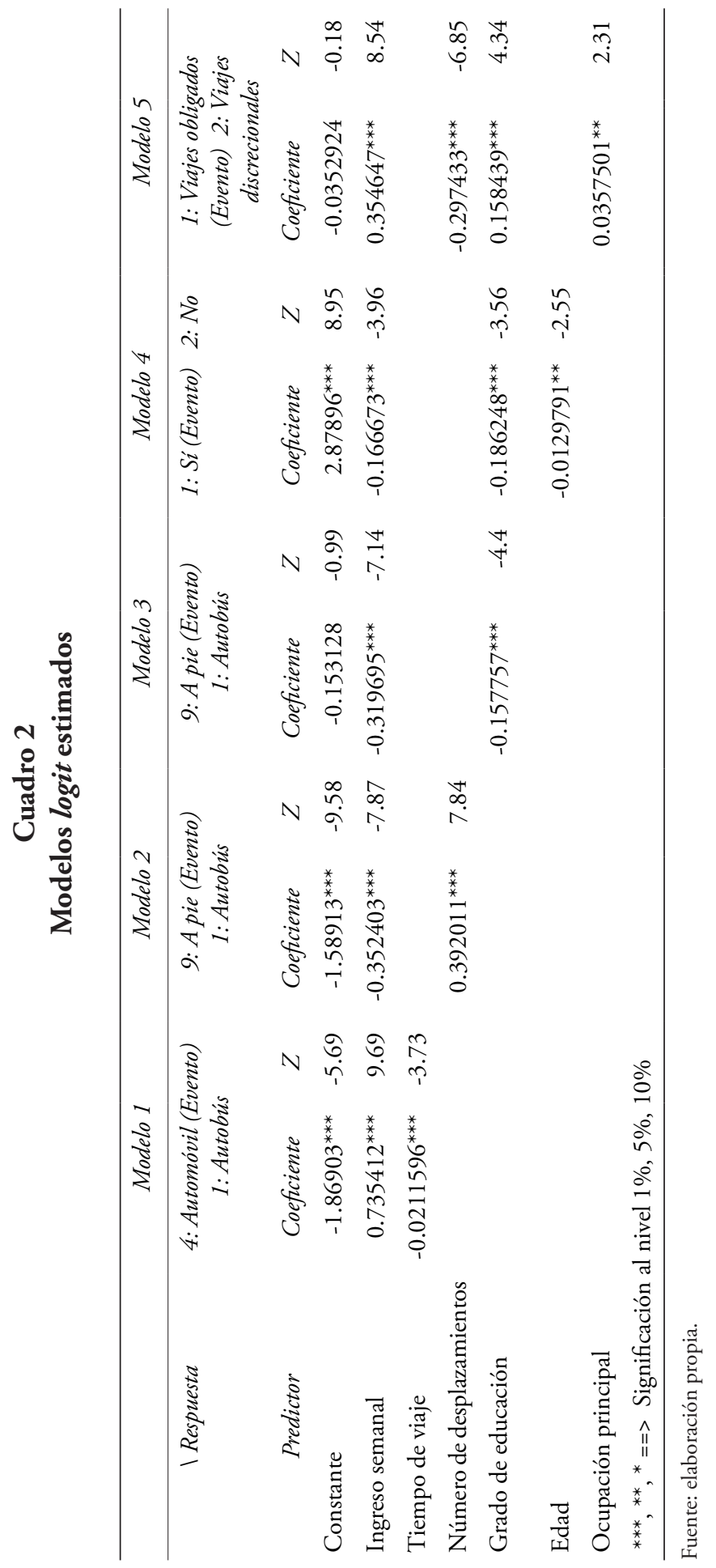


respecto a los usuarios de transporte público. El signo negativo en el tiempo de viaje en vehículo también refleja una menor utilidad para el usuario.

\subsubsection{Entre el transporte público y los viajes a pie}

Se modeló la elección de los desplazamientos a pie (9) y en autobús (1), dos de los varios modelos estimados son estadísticamente significativos para representar la probabilidad de elección de dichos medios de transporte (modelo 2 y 3 del cuadro 2). Ambos modelos contienen el ingreso como variable explicativa y de magnitud considerable. En el modelo 2 se consideró el ingreso y el número de desplazamientos de los individuos, en él se observa que la magnitud de los coeficientes es muy similar, no obstante, el signo del ingreso refleja una menor utilidad para los individuos en la elección de sus desplazamientos a pie, mismos que realizan un mayor número de desplazamientos respecto a los de autobús. En el modelo 3 se consideró el ingreso y el grado de educación de los individuos, el cociente entre ambos coeficientes fue de alrededor de dos, y ambas variables reflejaron una menor utilidad en la elección de desplazamientos a pie. En ambos modelos el ingreso mostró una menor utilidad al momento de la elección de desplazarse a pie.

\subsubsection{Entre la utilización o no de un nuevo sistema de transporte público}

Una de las preguntas del cuestionario fue dirigida a los no usuarios de TP, una preferencia declarada (preferencia de elección en escenarios hipotéticos) (Sánchez y Romero, 2010) en la cual se les preguntó sobre si emplearían dicho medio en caso de una modernización y mayor calidad del sistema. La estadística descriptiva se expuso en el apartado 4.6.1. y en el modelo 4 del cuadro 2 se muestra el mejor modelo logit estimado. Los coeficientes de ingreso y grado de educación presentan magnitudes similares, mientras la magnitud del coeficiente de edad es catorce veces inferior al grado de educación. A partir de lo observado en el modelo se puede afirmar que en la elección de un nuevo sistema de transporte público induce una menor utilidad el mayor ingreso y grado de educación de los individuos.

\subsubsection{Entre los viajes obligados y los viajes discrecionales}

Se modeló la probabilidad de que los individuos realicen sólo viajes obligados, entendiendo éstos como los viajes al trabajo (en este caso no se incluyeron los viajes por motivo de estudio) frente a los que además de su movilidad obligada realizan también viajes discrecionales u opcionales 
(viajes por compras, sociales y recreacionales) en días laborables. El modelo 5 del cuadro 2 muestra que las variables significativas en orden de magnitud de sus coeficientes son el ingreso, el número de desplazamientos al día, el grado de educación y la ocupación principal. Es de interés observar la menor utilidad que para el individuo representa el número de desplazamientos diarios, lo que relaciona que un individuo que realiza mayor número de desplazamientos presente una mayor probabilidad de que éstos, en parte, sean discrecionales; y a la vez, el ingreso tiene una magnitud significativa en su realización, tal y como se observa en la gráfica Ix, la cual muestra que el número de desplazamientos discrecionales se incrementa con el ingreso.

\section{Gráfica IX \\ Ingreso y tasas de viajes discrecionales en un día típico laboral}

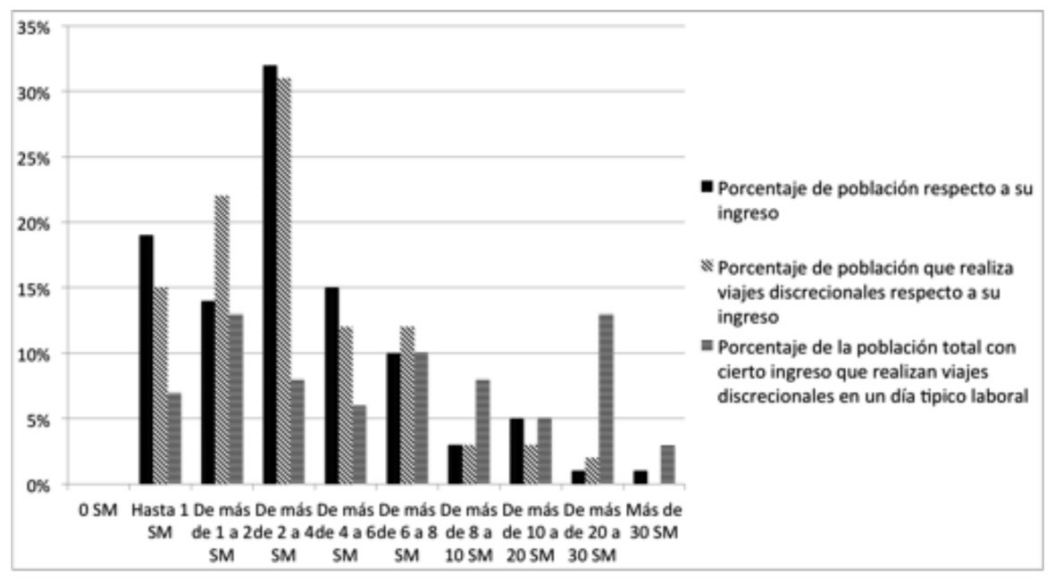

Fuente: elaboración propia.

\subsubsection{Entre zonas con ingreso medio alto y zonas con ingreso medio bajo}

Se compararon zonas de ingreso económico medio-alto (denominadas zonas residenciales) y zonas de ingreso económico medio-bajo (denominadas zonas obreras) en la elección de desplazarse en automóvil o transporte público, los siguientes modelos fueron obtenidos:

$$
\begin{aligned}
& \text { Vauto }=-4.37910+1.50536 \text { Ingreso }-0.0212686 \text { Tiempo de viaje } \\
& \quad(\text { Zonas residenciales }) \\
& \text { Vauto }=-3.93668+0.708541 \text { Ingreso }+0.0350151 \text { Tiempo de viaje } \\
& \quad(\text { Zonas obreras })
\end{aligned}
$$


$\mathrm{Al}$ analizar los coeficientes se observa que factores que no son el ingreso y tiempo de viaje tienen un menor impacto en las zonas residenciales al momento de elegir el automóvil como medio de transporte respecto al тр. La magnitud del coeficiente de ingreso en las zonas residenciales es $200 \%$ mayor respecto a las zonas obreras, por ello, la importancia del ingreso es mayor en las zonas residenciales.

El tiempo de viaje en vehiculo induce menor utilidad para los individuos de las zonas residenciales en la elección del auto, mientras que a los individuos de las zonas obreras el tiempo de viaje les presenta mayor utilidad debido a que los tiempos en auto son menores a los del тр. En las zonas residenciales, los pocos desplazamientos en TP son realizados principalmente por los hijos de las familias que viajan a sus centros escolares, situados a escaso tiempo. El percibir salario o ser dependiente, también es un punto de consideración en ambas zonas, que refleja pesos muy similares en sus coeficientes, como se observa en los siguientes modelos:

$$
\begin{array}{ll}
\text { Vauto }=-0.510826+3.45526 \text { Percibe salario } & \text { (Zonas residenciales }) \\
\text { Vauto }=-3.29584+3.25810 \text { Percibe salario } & \text { (Zonas obreras })
\end{array}
$$

\section{Conclusiones}

La investigación refleja que el ingreso del individuo contribuye significativamente en la elección del medio de transporte en la zcQ, lo que cumple la primera hipótesis de esta investigación. Los modelos logit corroboran y verifican la importancia de dicha variable como factor del sujeto en la elección de su medio de transporte. En la comparación, realizada con individuos de zonas con ingreso medio-alto y zonas con ingreso mediobajo, es de interés la variación del signo en la percepción del tiempo de viaje debido al beneficio inducido en los individuos de las zonas de ingreso medio-bajo al contar con un vehículo, ésta sería una línea de investigación futura que se adentre en las variaciones de la atractividad de diferentes medios en la diversidad socioeconómica reflejada en el contenido de la presente investigación, lo que ayudaría a planificar políticas de transporte adecuadas a las características socioeconómicas locales, generando modelos propios y no duplicando lo realizado en otros países.

Esta aproximación permitiría realizar estudios con un menor grado de fracaso debido a que los condicionantes son bastante diferentes, como se ha demostrado en investigaciones latinoamericanas reportadas por García (2006). Esto es, se podría trabajar individualmente en los diversos estratos socioeconómicos de las zonas determinando las políticas a nivel micro, para posteriormente englobarlas en el sistema, pues en ciudades como la del caso de estudio se presenta una fuerte disparidad socioeco- 
nómica zonal, la cual llega a presentar mezclas de zonas de ingreso alto colindantes a zonas de bajo ingreso. Así, conjugando los parámetros culturales, urbanísticos y el ritmo de desarrollo, diseñar las políticas de planificación para que los individuos se distribuyan en el sistema de una manera determinada.

El género también es un parámetro de interés, se observa un mayor número de desplazamientos realizados por varones, así como que éstos tienen mayor preferencia a emplear el vehículo privado cuando sus condiciones económicas lo permiten. La tasa de producción de viajes se ha incrementado en los últimos años, pues en el 2002 ésta era de 1.53 viajes por habitante (Transconsult, 2004), mientras que esta investigación obtuvo una tasa de 2.45 viajes por persona en un día típico laboral para el año 2010.

Si bien, la tasa de producción de viajes se ha incrementado, otros factores como la misma demanda, las necesidades de infraestructura y la no mejora en el sistema de transporte masivo, inducen a que la mayoría de los habitantes de la zCQ den una nota reprobatoria a las condiciones actuales para desplazarse en su ciudad, son los usuarios de тр los que peor percepción tienen, pues las mismas características del sistema influyen en su apreciación.

En este sentido, la misma calidad de explotación influye como efecto disuasor en el empleo del TP, si bien se observa un interés en los usuarios del resto de modos de transporte, la calidad del sistema influye determinantemente en su no empleo, verificando la segunda y tercera hipótesis planteada al inicio de esta investigación. Es posible que se presenten estas características de forma recurrente en otras ciudades mexicanas, lo que influye cada día en la necesidad de mayor capacidad vial debida a la demanda motivada por la preferencia al vehículo privado, lo que está afectando la sostenibilidad de las ciudades en términos de la movilidad y también de la calidad ambiental. Lo anterior es preocupante y se constata al observar que el vehículo privado ha incrementado su empleo en los últimos años en la zCQ, pues en el 2004, 39.7\% de los desplazamientos se realizaban en este medio y esta investigación arrojó una tasa del $47.92 \%$.

En cuanto al TP, éste es el medio más empleado en los desplazamientos de los habitantes de la zcQ, no obstante, su uso se presenta básicamente por necesidad, pues mayoritariamente es empleado por personas de bajos ingresos económicos y dependientes, ya que la misma calidad del servicio no lo hace atractivo frente al automóvil.

El número de desplazamientos en automóvil como conductor registró el segundo porcentaje más alto de utilización (no obstante si ańadimos los desplazamientos realizados como acompañante, superaría al número de desplazamientos del TP como el medio transporte más empleado por 
los habitantes de la zCQ). Un alto porcentaje de los desplazamientos en este medio son realizados por varones, mientras que en TP las mujeres superan a los varones en el porcentaje de viajes. Como ya se expuso, los usuarios del automóvil reflejan un mayor ingreso económico respecto a los usuarios del TP.

Si bien, un alto porcentaje (87.91\%) de los usuarios de automóvil son individuos que perciben un salario, en los usuarios de TP esta tasa decrece $(63.8 \%)$ y por ende, muestra que la mayoría de las personas dependientes emplean dicho medio de transporte. Respecto a los medios no motorizados, la mayoría de los desplazamientos a pie son efectuados por mujeres, mientras que en bicicleta la mayoría son realizados por varones. Un alto porcentaje de los peatones son estudiantes, seguido de personas que se dedican al hogar, es decir, individuos dependientes. Además, se observan cinco zonas definidas en la realización de los desplazamientos, resultado derivado aparentemente del efecto barrera que inducen los principales corredores viarios en la permeabilidad del territorio. Por lo que se refiere a los traslados en bicicleta, en su mayoría son realizados por empleados, observando que un alto porcentaje percibe salario.

En cuanto al por qué no se emplea el TP, el principal motivo de los automovilistas es la comodidad, seguido del tiempo de trayecto y el trato al usuario (sin considerar aquellos a los que no les interesa), mientras que para los individuos que realizan desplazamientos a pie, el trato al usuario es el principal disuasor, seguido de la comodidad y el costo del viaje (de igual forma, sin considerar individuos que no les interesa). Si bien, es una constante el trato al usuario y la comodidad, se vuelve a reflejar cómo el ingreso tiene peso en la elección del medio, ya que éste aparece como disuasor de los individuos que se desplazan a pie.

La correlación entre la estructura espacial urbana y el transporte se muestra reflejada en la duración y la distancia de viaje. Un punto disuasor importante para los usuarios de automóvil es el tiempo de viaje en TP, si bien la investigación muestra una distribución relativamente similar entre el porcentaje de desplazamientos y el rango de tiempo empleado entre los usuarios del automóvil y del TP, podríamos suponer que son competentes ambos medios, lo anterior puede ser explicado, ya que al no existir carriles preferenciales, el transporte público tiende a emplear indistintamente todos los carriles de las vialidades, además las mismas características de explotación del sistema propician una lucha entre los choferes por el pasaje, esta mezcla, y la influencia de una flota superior a la requerida para la demanda satura las vialidades y su comportamiento por ende tiene influencia en los tiempos de viaje para los usuarios del vehículo privado.

Sin embargo, al considerar el tiempo de acceso a la parada y la espera observamos que las tasas de desplazamientos en los rangos de tiempo de 
viaje total se incrementan notablemente, y por ello baja la competitividad del sistema.

Esta investigación reflejó un peso importante del gasto como porcentaje de ingreso destinado a los usuarios cautivos del transporte público, principalmente de las personas dependientes. No obstante, es de considerar que $42.11 \%$ de los usuarios de transporte público invierten cerca de $8 \%$ de su ingreso diario para poder acceder al mercado laboral. Este punto, como otros, requieren un mayor nivel de análisis. El presente artículo se enfocó a describir los desplazamientos en una ciudad media mexicana y los parámetros socioeconómicos que los describen, comprobando las tres hipótesis de partida. Las posibles líneas de investigación futura que se proponen se enfocan a comparar la elección de medios dependiendo de las características socioeconómicas zonales y el impacto del gasto familiar en transporte.

\section{Agradecimientos}

Se extiende un profundo agradecimiento por su gran colaboración a los más de cien alumnos de la Facultad de Ciencias Políticas y Sociales y de la Facultad de Ingeniería de la Universidad Autónoma de Querétaro por su disposición en el proceso de capacitación y su entrega para realizar las entrevistas de esta investigación. Asimismo, a la maestra Rocío Minerva Hidalgo, al maestro Agustín Osornio y al doctor Roberto de la Llata, por sus amplios comentarios y recomendaciones en el proceso de diseño del cuestionario; así como las valiosas observaciones de los dictaminadores anónimos en la revisión temprana del documento. Los autores son los únicos responsables de todos los datos contenidos en éste artículo y pueden ser solicitados a través de la UAQ.

\section{Bibliografía}

Alonso, William (1964), Location and land use: towards a general theory of land rent, Harvard University Press, Cambridge.

Bruton, Michael (1985), Introduction to transportation planning, Hutchinson, Londres.

Casado, José (2008), "Estudios sobre movilidad cotidiana en México", Scripta Nova, XII (273), Universidad de Barcelona, Barcelona, <www.ub.edu/geocrit/sn/sn-273.htm>, 11 de septiembre de 2012. 
Cefp (Centro de Estudios de las Finanzas Públicas) (2013), "Tipo de cambio nominal FIX, 1980-2012 (Para solventar obligaciones en moneda extranjera)", Cámara de Diputados, <http://www3.diputados.gob.mx/camara/001_diputados/006_centros_de_estudio/02_centro_de_estudios_de_finanzas_publicas__1/005_ indicadores_y_estadisticas/01_historicas/01_ind_macroeconomicos_1980_2012/07_tipo_de_cambio>, 11 de septiembre de 2013.

CQRN (Centro Queretano de Recursos Naturales) (2003), Reordenamiento del sistema de transporte público de pasajeros de la Zona Metropolitana de Querétaro, Concyteq, Querétaro.

Cervero, Robert (1998), The transit metropolis: a global inquiry, Island Press, Washington.

Cobo, Mauricio (2008), "Sistemas de transporte y crecimiento urbano: hacia una ciudad densa y policéntrica", Cuadernos de arquitectura y nuevo urbanismo, edición especial octubre, Instituto Tecnológico de Estudios Superiores de Monterrey, Querétaro, pp. 20-24.

Delgado, Javier, Luis Chías, Mauricio Ricárdez, Anuar Martínez y Tonatiuh Suárez (2003), "Vialidad y vialidades en la ciudad de México", Ciencias, 70, unam, México, pp. 50-64.

Fuentes, César (2009), "La estructura espacial urbana y accesibilidad diferenciada a centros de empleo en Ciudad Juárez, Chihuahua", Región y Sociedad, XXI (44), El Colegio de Sonora, Hermosillo, pp. 117-144.

Gannon, Colin, Kenneth Gwilliam, Zhi Liu, y Christina Malmberg (2001), "Transport: infrastructure and services", Draft for comments, World Bank, Washington, pp 1-61.

García, José (2006), "Bases iniciales para el mejoramiento del servicio de transporte público en una ciudad venezolana”, Economía, Sociedad y Territorio, VI (22), El Colegio Mexiquense, A. C., Zinacantepec, pp. 1-31.

Giacobbe, Nora, Andrea Álvarez y Laura Pérez (2009), “Aportes al estudio de la accesibilidad en el área metropolitana de Buenos Aires, el caso del municipio de Lanús", ponencia presentada en el XV 
Congreso Latinoamericano de Transporte Público y Urbano, 31 de marzo-3 de abril, Buenos Aires.

Giuliano, Genevieve y Kenneth Small (1993), "Is the journey to work explained by urban structure?”, Urban Studies, 30, Sage publicatios, Glasgow, pp. 1485-1500.

Gutiérrez, Javier, y Juan García (2005), Movilidad por motivo de trabajo en la comunidad de Madrid, Universidad Complutense de Madrid, Madrid.

Henry, Etienne (1998), "Regards sur la mobilité urbaine a Amerique latine", Espaces et Societés, 2, Toulouse, pp. 52-58.

Hook, Walter (2003), "Preserving and expanding the role of non motorized transport", Sustainable transport: a sourcebook for policy makers in developing cities, Deutsche Gesellschaft fur Technische Zusammenarbeit, module 2, Bonn, 1-34 pp.

Ibeas, Ángel, Felipe González, Luigi Dell Olio y José Moura (2007), Manual de encuestas de movilidad (preferencias reveladas), Editorial Escuela Técnica Superior de Ingenieros de Caminos, Canales y Puertos de Santander, Santander.

INEGI (Instituto Nacional de Estadística, Geografía e Informática) (2010), “Censo de Población y Vivienda 2010”, www.inegi.org.mx, marzo de 2012.

Junyent, Rosa (2001), "Evaluating the social impact of urban highways. Application to the outer ring road in Barcelona", en Clara Cardia y Rosa Junyent (eds.), Impacts of mayor transport infraestructures on the quality of urban shape, Directorate-General for Research, European Commission, Luxembourg, pp. 9-28.

Merlin, Pierre (1996), "Los factores de una política de transporte", en Ricardo Montezuma (ed.), El transporte urbano: un desafio para el próximo milenio, CEJA, Bogotá, pp. 23-73.

Mills, Eswin (1972), Urban economics, Scott, Foresman and Company, Glenview. 
Molinero, Ángel e Ignacio Sánchez (2003), Transporte público: planeación, diseño, operación y administración, Quinta del agua, México.

Mundó, Josefina (2002), "El transporte colectivo urbano: aplicación del enfoque de sistemas para un mejor servicio", Fermentum. Revista Venezolana de Sociología y Antropología, 12 (34), Mérida, Venezuela, pp. 285-302.

Muth, Richard (1969), Cities and housing, University of Chicago Press, Chicago.

Obregón-Biosca, Saúl (2010), "Estudio comparativo del impacto en el desarrollo socioeconómico en dos carreteras: Eix Transversal de Catalunya, España y MEX120, México", Economía Sociedad y Territorio, X (32), El Colegio Mexiquense, A. c., Zinacantepec, pp. 1-47.

Ocaña, Rosa y Joheni Urdaneta (2005), “Participación de los municipios en la formación de la política nacional de transporte urbano en Venezuela", Revista Venezolana de Gerencia, 10 (030), Maracaibo, pp. 196-210.

Ortúzar, Juan de Dios (2000), Modelos de demanda de transporte, Alfaomega, México.

Ortúzar, Juan de Dios y Luis Willumsen (2008), Modelos de transporte, Universidad de Cantabria, Santander.

Pardo, Carlos (2005), "Salida de emergencia: reflexiones sociales sobre las políticas del transporte", Universitas Psychologica, 4 (003), Pontificia Universidad Javeriana, Bogotá, pp. 271-284.

Picco, Alicia María, Clyde Elisa Charre y Nicolás Álvarez (2010), “Aportes de la metodología estadística a los modelos de demanda de transporte", ponencia presentada en el XVI Congreso Latinoamericano de Transporte Público y Urbano, 6-8 de octubre, México.

Rabaza, Jerónimo (2009), “Tamaño vehicular óptimo para el servicio público de superficie”, tesis de grado de ingeniería, Universitat Politécnica de Catalunya, Barcelona. 
Ramírez, Enrique (2012), "Comparación de la interacción vehicular inducida por el empleo de carriles preferenciales para el transporte público utilizando microsimulación de tráfico", tesis de maestría, Universidad Autónoma de Querétaro, Querétaro.

Rojas, Fernando y Carlos Mello (2005), "El transporte público colectivo en Curitiba y Bogotá", Revista de Ingeniería, 21, Universidad de los Andes, Bogotá, pp. 106-115.

Sánchez, Óscar y Javier Romero (2010), "Factores de calidad del servicio de transporte público de pasajeros: estudio de caso de la ciudad de Toluca, México", Economía Sociedad y Territorio, X (32), El Colegio Mexiquense, A. C., Zinacantepec, pp. 49-80.

Sedesol (Secretaría de Desarrollo Social) (s.f.), "Programa de asistencia técnica en transporte urbano para las ciudades medias mexicanas", Secretaría de Desarrollo Social, México.

Sobrino, Jaime (2007), "Patrones de dispersión intrametropolitano en México", Estudios Demográficos y Urbanos, 22 (3), El Colegio de México, México, pp. 583-617.

Suárez, Manuel y Javier Delgado (2007), "Estructura y eficiencia urbanas. Accesibilidad a empleos, localización residencial e ingreso en la ZMCM 1990-2000", Economía, Sociedad y Territorio, VI (23), El Colegio Mexiquense, A. c., Zinacantepec, pp. 693-724.

Suárez, Manuel y Javier Delgado (2010), "Patrones de movilidad residencial en la ciudad de México como evidencia de co-localización de población y empleos", EURE, 36 (107), Pontificia Universidad Católica de Chile, Santiago, pp. 067-091.

Susino, Joaquín, José Manuel Casado y José María Feria (2007), “Transformaciones sociales y territoriales en el incremento de la movilidad por razón de trabajo en Andalucía", Cuadernos de Geografía, 81 (82), Universidad Nacional de Colombia, Bogotá, pp. 71-92.

Transconsult (2004), "Plan integral de transporte colectivo en la Zona Metropolitana de Querétaro", Reporte técnico, México. 
Valero, Ángeles (1984), "Movilidad espacial en Madrid”, Anales de Geografía de la Universidad Complutense, 4, Universidad Complutense, Madrid, pp. 207-225.

Recibido: 24 de abril de 2012. Reenviado: 10 de septiembre de 2013. Aceptado: 15 de octubre de 2013.

Saúl Antonio Obregón-Biosca. Mexicano. Ingeniero civil por la Universidad Autónoma de Querétaro (UAQ). Suficiencia investigadora en urbaníistica, maestro en ingeniería y doctor en ingeniería por el Departamento de Infraestructuras del Transporte y Ordenación del Territorio de la Universidad Politécnica de Cataluña. Actualmente es profesor e investigador en la División de Estudios de Posgrado de la Facultad de Ingeniería de la UAQ, en donde coordina la maestría en Vías Terrestres, Transporte y Logística. Es miembro del Sistema Nacional de Investigadores, nivel I. Su línea de investigación actual se centra en el análisis de movilidad metropolitana y externalidades del transporte. Entre sus últimas publicaciones como autor y coautor destacan: "El impacto de las carreteras en el desarrollo socioeconómico. Comparación de dos casos de estudio: el Eix Transversal de Catalunya en España y la MEX120 en México", Economía, Sociedad y Territorio, X (32), El Colegio Mexiquense, A. C., Zinacantepec, pp. 1-40 (2010); "An empirical approach for experimental assessments in urban freight", Scientific Research and Essays, 7 (20), Nigeria, pp. 1917-1934 (2012); "Improved accessibility and commuting changes. Case study: C-25 road axle in Catalonia (Spain)", en Srinivasan Sunderasan (ed.), Externality: Economics, Management and Outcomes, Nova Science, New York, pp. 81-109 (2012); "Un referencial para evaluar la gestión pública en transporte urbano de carga”, Revista Gestión y Politica Pública, XXII (2), Centro de Investigación y Docencia Económicas A. C., México, pp. 313-354 (2013); "Testing a new methodology to assess urban freight systems through the analytic hierarchy process", Modern Traffic and Transportation Engineering Research, 2 (2), American V-King Scientific Publishing, New York, pp. 78-86 (2013), "Road transport infrastructure and manufacturing location: an empirical evidence and comparative study between Tijuana and Nuevo Laredo, Mexico", Frontera Norte, 26 (52), El Colegio de la Frontera Norte, Tijuana, pp. 109-132 (2014).

Eduardo Betanzo-Quezada. Mexicano. Ingeniero civil por la Universidad Nacional Autónoma de México y doctor en Ciencias Económicas 
por el Centre de Recherche sur le transport et la Logistique (CRET-Log) de la Universidad de Aix-Marseille II, Francia. Actualmente es investigador de la División de de Investigación y Posgrado de la Facultad de Ingeniería de la UAQ. Fue investigador y jefe de la Unidad de Estudios Económicos del Instituto Mexicano del Transporte. Es miembro del Sistema Nacional de Investigador, nivel I. Su principal línea de investigación es sistemas de transporte y logística urbana. Entre sus últimas publicaciones como primer autor destacan: "Un referencial para evaluar la gestión pública en transporte urbano de carga", Revista Gestión y Política Pública, XXII (2), Centro de Investigación y Docencia Económicas, A.C. México, pp. 313-354 (2013). "An empirical approach for experimental assessments in urban freight," Scientific Research and Essays, 7 (20), Academic Journals, New York, pp. 1917-1934 (2012); "Una aproximación metodológica al estudio integrado del transporte urbano de carga: el caso de la Zona Metropolitana de Querétaro en México", Revista Latinoamericana de Estudios Urbanos y Regionales, 37 (112), Pontificia Universidad Católica de Chile, Santiago, pp. 63-87 (2011); "An urban freight transport index", Procedia Social and Behavioral Sciences, 2, Elsevier, Amsterdam, pp. 6312-6322 (2010). 